\title{
Delegated Portfolio Management, Benchmarking, and the Effects on Financial Markets
}




\section{WP/15/198}

\section{IMF Working Paper}

\section{Delegated Portfolio Management, Benchmarking, and the Effects on Financial Markets}

by Deniz Igan and Marcelo Pinheiro

IMF Working Papers describe research in progress by the author(s) and are published to elicit comments and to encourage debate. The views expressed in IMF Working Papers are those of the author(s) and do not necessarily represent the views of the IMF, its Executive Board, or IMF management.
I N
N T

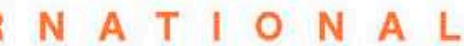
$M O N E T A R Y$
F U N D 


\title{
IMF Working Paper
}

Research Department

\section{Delegated Portfolio Management, Benchmarking, and the Effects on}

\author{
Financial Markets
}

Prepared by Deniz Igan and Marcelo Pinheiro

Authorized for distribution by Giovanni Dell'Ariccia

September 2015

IMF Working Papers describe research in progress by the author(s) and are published to elicit comments and to encourage debate. The views expressed in IMF Working Papers are those of the author(s) and do not necessarily represent the views of the IMF, its Executive Board, or IMF management.

\begin{abstract}
We analyze the implications of linking the compensation of fund managers to the return of their portfolio relative to that of a benchmark - a common solution to the agency problem in delegated portfolio management. In the presence of such relativeperformance-based objectives, investors have reduced expected utility but markets are typically more informative and deeper. Furthermore, in a multiple asset/market framework we show that (i) relative performance concerns lead to an increase in the correlation between markets (financial contagion); (ii) benchmark inclusion increases price volatility; (iii) home bias emerges as a rational outcome. When information is costly, information acquisition is hindered and this attenuates the effects on informativeness and depth of the market.
\end{abstract}

JEL Classification Numbers: G11, G23

Keywords: Delegated portfolio management, Informativeness, Liquidity, Contagion, Home bias

Authors’ E-Mail Addresses: digan@imf.org; pinheirom@pcaobus.org ${ }^{\dagger}$

\footnotetext{
† The views expressed in this paper are the authors' personal views and do not necessarily reflect the views of the PCAOB Board as a whole or other staff of the PCAOB. We would like to thank Franklin Allen, Markus Brunnermeier, Aureo de Paula, Gaston Gelos, and Hélène Rey for helpful discussions. All remaining errors are our own.
} 


\section{Contents}

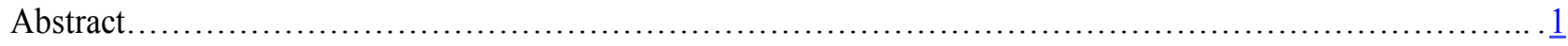

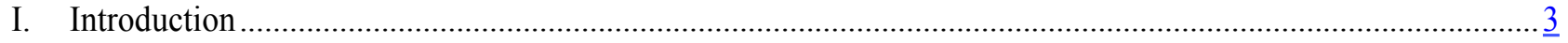

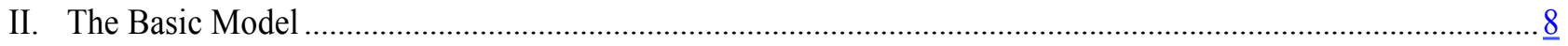

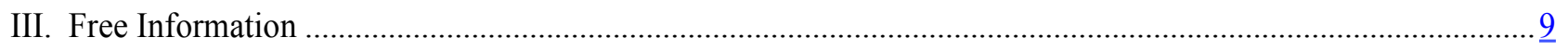

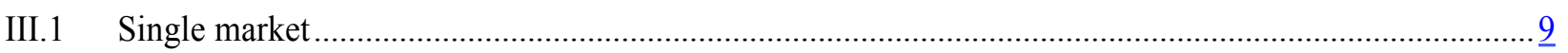

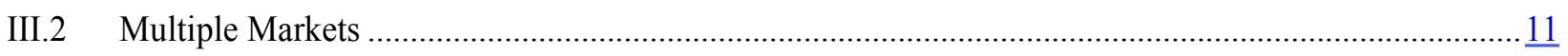

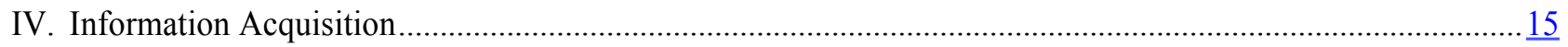

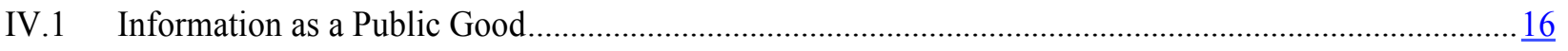

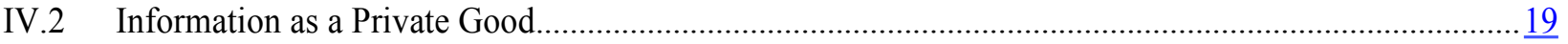

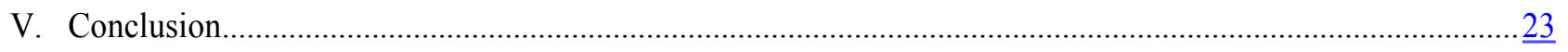

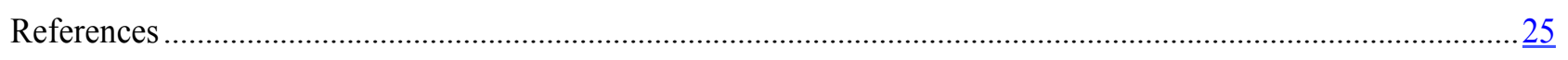

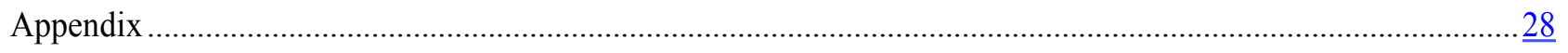

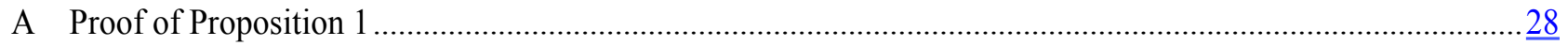

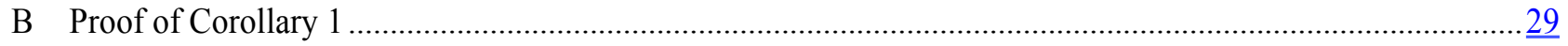

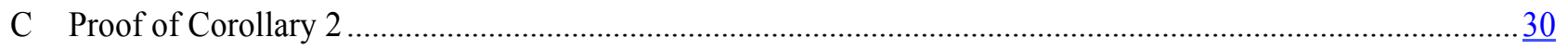

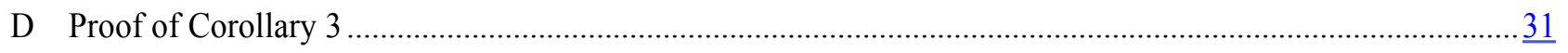

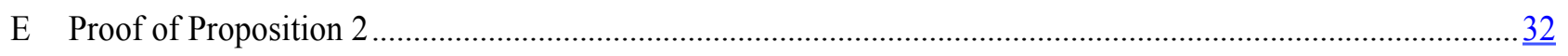

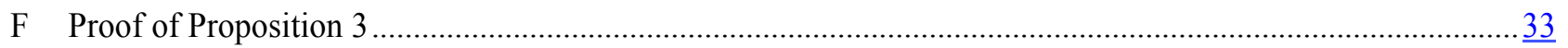

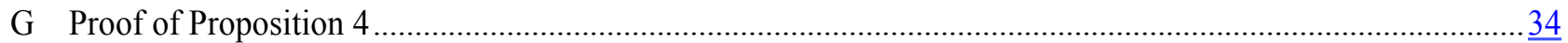




\section{Introduction}

An interesting omission in standard portfolio choice theory is that professional portfolio managers such as mutual, pension, and hedge fund managers are ignored and investors are assumed to directly manage their own portfolios. This assumption depicted the equity market in the mid-1950s well but it no longer does: direct holdings of corporate equity by the household sector has fallen from 99 percent in 1945 to 47 percent in $2010 .^{1}$

Recently, two related strands of literature have aimed to answer some of the questions raised by the issue of delegated portfolio management and the associated agency problems in modern markets. The first of these strands concentrates on the determination of optimal contracts to solve the agency problem between the portfolio manager and the investor. The optimal contract is often depicted as one that rewards performance relative to a benchmark. The other strand investigates whether relative performance might lead a manager to change fund's risk exposure and if this behavior is linked to the manager's compensation package.

In this paper, we seek to expand the insights offered in the literature along the second strand. Our focus is not on optimal contracts. Instead, we take the optimal contract as given, carrying the properties commonly observed in practice. $^{2}$ Then, we analyze the effects of the adoption of relative performance pay for fund managers. Differently from the previous literature, we move away from the questions about risk exposure, exploring other interesting implications for the market microstructure. First, we show that if fund managers are rewarded based on a relative performance measure, there can be deleterious effects for investors. More precisely, investors will have a lower expected utility. However, markets will typically be more informative and deeper, provided that information is free. We also observe an increase in the correlation between markets. That is, we

\footnotetext{
${ }^{1}$ Based on Flow of Funds data from the Federal Reserve Board (Table B.100.e). Note that these figures actually understate the "influence" of financial intermediaries on the individual portfolio decisions since, according to Investment Company Institute, 67 percent of individual investors seek services of financial advisors when making their decisions.

${ }^{2}$ Note that the form of relative performance objectives can be flexible. These objectives do not have to be spelled out in formal contracts but may emerge as a result of competitive forces and/or behavioral factors (e.g., keeping up with the Joneses). We do use the words "objective", "contract", and "concern" almost interchangably throughout.
} 
show that the higher the importance of relative performance, the higher the correlation between two separate markets. And, we show that a stock that is included in the benchmark experiences an increase in its price volatility. Finally, information acquisition may be hindered by these types of contracts. This last effect may, ex ante, reduce the informativeness and depth of the market. So, even though conditional on information being acquired markets function better, less information acquisition may emerge and act in a countervailing way.

Investors usually base their investment decisions on fund performance typically choosing funds that have high returns compared to similar funds (see, among others, Chevalier and Ellison (1997) and Sirri and Tufano (1998)). This behavior, combined with the usual fee structure in a fund (charged as a percentage of funds), leads to relative performance objectives for fund managers: you are only doing well in as much as you are doing better than your competitor. So, our assumption of relative performance contracts is mostly a modeling short-cut to be interpreted as a reduced form of this more elaborate situation. Palomino (2005) shows that if investors use a relative performance rule to evaluate funds and allocate money into them, and managers receive an assetbased compensation, then this translates into relative performance objectives for fund managers.

In the model, there are two investment funds in a market for an asset. Each fund manager observes a signal concerning the profitability of the risky asset. Markets function like in Kyle (1985), with the difference that we have two insiders, signals are noisy and, more importantly, each manager's payoff depends on his performance, as well as on the performance of the other manager. Fund owners reward the managers, the fund investors, and keep the rest to themselves. We analyze standard measures of market efficiency, and how the fund investors are affected by the presence of this relative performance objective function. We also analyze how the managers' own well-being is affected by accepting such contracts.

We extend the model to allow for two separate markets for two assets, and show that the correlation across markets is increasing in the measure of relative performance. In other words, contagion effects may appear, or be exacerbated by the presence of such contracts. In a similar vein, with two assets but both traded in the same market, we show that inclusion of a stock in the benchmark leads its price to experience higher price volatility. And, in another extension, we show 
how relative performance contracts may lead to a form of home bias.

Finally, we allow the choice to be informed to be endogenous, with costly signals. Specifically, we allow for two different information structures: public or private costly information. Under the first structure, either all fund managers pay the cost of acquiring information and all become informed or none of them do so. Under the second structure, each manager may decide independently. We show that, probabilistically, an increase in the importance of relative performance reduces the availability of informed equilibrium. That is, the more the managers' pay depend on relative performance, the lower the probability that either one decides to acquire information. Therefore, even though conditional on having informed agents the informativeness of prices is increasing on the importance of relative performance, we see that ex ante this effect may be attenuated or cancelled by the fact that the chance of having an informed equilibrium is reduced. This countervailing effect is also present when analyzing the expected price response to trades (a measure inversely related to market depth).

Our paper relates and contributes to the literature in several ways. Some papers study the optimal portfolio strategy of a manager receiving fees that depend on relative performance (see, among others, Grinblatt and Titman (1989), Brown, Harlow, and Starks (1996), Chen and Pennacchi (1999), Eichberger, Grant, and King (1999), and Goriaev, Palomino, and Prat (2000)). The general focus in these studies is on the effects on portfolio riskiness with results showing that managers tend to over-bear risk in order to beat the benchmark, especially when they are behind in the game. Our model delivers a similar result, although in a slightly different manner (and this result is not central to our paper). Since we adopt a Kyle-type framework, what we show is that managers trade more aggressively, i.e., put more weight on their signal, as the importance of relative performance increases. Since, for a given signal, managers increase their trading activity, this can be loosely interpreted as an increase in risk-taking behavior. The literature has also provided empirical evidence of this type of behavior, hence we take this as an already tested implication of our model. ${ }^{3}$

\footnotetext{
${ }^{3}$ See Goriaev, Palomino, and Prat (2000) and references therein. Some studies argue that increased risk aversion leads managers to retrench and to more closely mimic their competitors' portfolios. For instance, Broner, Gelos, and Reinhart (2006) empirically show that, when funds' returns are below average, they adjust their holdings toward the
} 
In a related paper (and as mentioned earlier), Palomino (2005) develops a model that indirectly generates the same type of objectives for managers and shows that, with entry and exit by funds (with exogenously given differential ability), these objectives may lead to survival of better-quality funds and, hence, higher expected returns for investors. We differ in our approach by assuming a fixed market structure (no entry), homogenous ability of funds with endogenous informational asymmetries and by analyzing the effects of varying the level of relative vis-à-vis absolute compensation on investors as well as on other market variables. Our results on investors' returns are in clear contrast to his. Since the modeling approaches are different, this, in and of itself, does not mean any immediate conflict. But it does point to the need of understanding the different forces at play: differential ability and information acquisition. In Palomino (2005), better-quality funds have a competitive advantage in acquiring information, and hence in equilibrium the market is populated by more informed individuals providing services to investors. In our setting, no fund has an edge and hence there is no inclination to have a more informative market. So, more concern about relative performance here leads to aggressive trading strategies and lower expected returns for investors, while in Palomino (2005) it leads to more high-quality funds entering the market (with better info) and hence investors having higher returns. However, in contradiction with empirical evidence on market efficiency (e.g., Berk and Green (2004)), Palomino's work seems to lead to a mutual fund industry that can outperform the market (passive strategy), while our model does not suffer from such a counter-intuitive implication. ${ }^{4}$ Finally, we also discuss home bias, contagion and addition to benchmarks, topics not discussed in Palomino (2005).

In another related paper, Cuoco and Kaniel (2011) examine the effects of delegated portfolio management on equilibrium asset prices assuming a contract for fund managers that is a generalization of the one postulated here. The main differences between the model here and their work rest on the assumed market structure and objectives. They analyze a problem under perfect competition concentrating on the potential for price effects on the stocks that are included in the average (or benchmark) portfolio. The seeming contradiction is likely a reflection of threshold effects. Shelef (2013), for example, provides theoretical and empirical evidence that risk taking is non-monotonic: managers who are very distant from the incentive threshold take less risk than those who are less distant but on average risk taking increases.

${ }^{4}$ Results on price informativeness and trading aggressiveness are similar across both papers. 
benchmark. ${ }^{5}$ They show that stocks that are included in the benchmark tend to have higher and more volatile prices than otherwise identical stocks. The analysis in this paper is under imperfect competition and, while replicating this volatility effect, aims at examining the effects of such contracts on the market microstructure, in terms of liquidity, price informativeness, cross-market correlation, and information acquisition. To the best of our knowledge, the results describing these effects are specific to this paper and have not been analyzed in the same setting elsewhere.

Finally, a different (and rather expansive) strand of the literature focuses on optimal contracts that solve/mitigate the agency problem inherit in delegated portfolio management. ${ }^{6}$ As mentioned above, in this paper we do not tackle this problem. Instead, we take the contract as given and analyze its effects.

From a regulator's perspective, the insights presented here open a range of questions. Most notably, there can be a trade-off between the benefits of aligning the principal's interests with those of the agent and the potential costs associated with the effects on contagion, volatility, and the informativeness of markets. What type of frameworks (in, e.g., setting fund managers' incentives and disclosure requirements) then could limit contagion and excessive volatility and maintain informativeness of markets? We leave it to future research to examine these more normative questions and the optimal ways to balance this trade-off.

The rest of this paper is organized as follows. Section II describes the basics of the model. In Section III, we analyze the effects of the presence of a relative performance-type contract for fund managers in a market where they have free access to information and derive the main results. In Section IV, we study the effects of relative performance on the decision to acquire information and discuss the differences that emerge from endogeneizing the information acquisition decision. Section V concludes.

\footnotetext{
${ }^{5}$ Brennan (1993) also considers the effects of such contracts on equilibrium expected returns and prices.

${ }^{6}$ This agency problem has been discussed in a number of papers, e.g., Starks (1987), Heinkel and Stoughton (1994), Admati and Pfleiderer (1997), Das and Sundaram (1998a,b), Ou-Yang (2003), and Dybvig, Farnsworth, and Carpenter (2010).
} 


\section{The Basic Model}

Throughout most of the paper, we assume that there are two mutual funds in a market for an asset. ${ }^{7}$ Each fund manager observes a signal concerning the profitability of the risky asset. ${ }^{8}$ Markets function like in Kyle (1985), with the difference that we have two insiders/managers and signals are noisy. More precisely, assume that the risky asset final payoff is given by

$$
\widetilde{v} \sim N\left(0, \sigma_{v}^{2}\right)
$$

Each manager observes a noisy signal about the final payoff

$$
\widetilde{s_{i}}=\widetilde{v}+\widetilde{\varepsilon}_{i}, i=1,2,
$$

with $v \perp \varepsilon_{i}$, and where the noise terms are jointly normal with $\operatorname{Var}\left(\widetilde{\varepsilon}_{i}\right)=\sigma_{\varepsilon}^{2}$. Furthermore, we assume that the necessary noise in the market comes from liquidity trades given by $\widetilde{u} \sim N\left(0, \sigma_{u}^{2}\right)$.

Each manager's payoff depends directly on his performance relative to a benchmark. We postulate the following form for manager $i$ 's objective:

$$
\max _{\alpha_{i}} \mathbb{E}\left\{\phi\left[\alpha_{i}(v-P)-\gamma \alpha_{j}(v-P)\right] \mid s_{i}\right\}
$$

where $P$ is price of the asset, $\alpha_{i}$ denotes the portfolio weights, $\phi$ is just a scaling factor, and $\gamma$ represents how much his payoff depends on relative performance. ${ }^{9}$ Fund managers' concern with relative performance such as this may arise if the fund uses a "fulcrum fee" or if they are rewarded based on the size of their fund and consumers invest more in funds that perform better. ${ }^{10}$

Fund owners pay managers as well as the investors. We assume that a proportion $\varsigma$ of this fund profits goes to investors. ${ }^{11}$ Therefore, the total expected cost for the owners of fund $i$ is

$$
\varsigma \mathbb{E}\left[\alpha_{i}^{*}(v-P)\right]+\phi \mathbb{E}\left[\left(\alpha_{i}^{*}-\gamma \alpha_{j}^{*}\right)(v-P)\right]=(\varsigma+\phi(1-\gamma)) \mathbb{E}\left[\alpha_{i}^{*}(v-P)\right],
$$

\footnotetext{
${ }^{7}$ This is without loss of generality. We could allow for more funds and results would be qualitatively the same.

${ }^{8}$ This signal may or may not be costly. We analyze both cases.

${ }^{9}$ This payoff function is a special case of the more general one assumed in Cuoco and Kaniel (2011).

${ }^{10}$ See, for instance, Palomino (2005).

${ }^{11}$ Since we have a static model, the fund payoff will also be the amount of money in the fund after the realization of the random variables. Hence, paying $\varsigma$ to investors is the same as charging a percentage fee on the amount of funds, i.e., the fee is $1-\varsigma$, a common practice.
} 
where $\alpha_{i}^{*}$ represents the solution to manager $i$ 's problem. The equality follows from the fact that we concentrate on a symmetric equilibrium and that the signals are i.i.d. Given this structure of contracts, a natural assumption is that $\varsigma+\phi(1-\gamma)<1$, to guarantee that owners are making positive expected profits:

$$
\mathbb{E}\left[\alpha_{i}^{*}(v-P)\right]-(\varsigma+\phi(1-\gamma)) \mathbb{E}\left[\alpha_{i}^{*}(v-P)\right]>0
$$

Finally, we assume that investors are risk-neutral and would like to maximize expected profits: $\varsigma \mathbb{E}\left[\alpha_{i}(v-p)\right]$.

Prices are determined by a risk-neutral competitive market maker that only observes aggregate market orders. As usual, the market maker is held down to a zero profit condition that translates into semi-strong efficiency of the market:

$$
P=\mathbb{E}\left[v \mid \alpha_{1}+\alpha_{2}+u\right]
$$

\section{Free Information}

In this section, we assume that the fund managers are endowed with rights to the information provided by the signals. Basically, they have free access to the signal, $s_{i}$. We divide the section into two subsections. In the first, we restrict attention to one market and present the results concerning investor's utility and market parameters' behavior as a function of the relative performance contract. In the second subsection, we allow for the existence of two separate markets and analyze the issue of cross-market contagion.

\section{III.1 Single market}

With this basic set-up at hand, we have the following proposition.

Proposition 1 A symmetric linear equilibrium of the market described is given by

$$
P=\lambda\left(\alpha_{1}+\alpha_{2}+u\right), \alpha_{i}=\beta \widetilde{s_{i}},
$$

with

$$
\beta=\sqrt{\frac{\sigma_{u}^{2}}{2(1-\gamma) \sigma_{v}^{2}+2 \sigma_{\varepsilon}^{2}}} \text { and } \lambda=\frac{2 \sigma_{v}^{2} \sqrt{\frac{\sigma_{u}^{2}}{2(1-\gamma) \sigma_{v}^{2}+2 \sigma_{\varepsilon}^{2}}}}{\left(2 \sigma_{v}^{2}+\sigma_{\varepsilon}^{2}\right) \frac{\sigma_{u}^{2}}{(1-\gamma) \sigma_{v}^{2}+\sigma_{\varepsilon}^{2}}+\sigma_{u}^{2}} \text {. }
$$


Proof. See Appendix.

We can now calculate the ex-ante expected profit of fund $i$ 's investors, as a function of $\gamma$.

Corollary 1 Ex-ante, investors expect to receive

$$
\mathbb{E}[\pi(\gamma)]=\varsigma \mathbb{E}\left[\alpha_{i}(v-P)\right]=\varsigma \sigma_{v}^{2} \sqrt{\frac{\sigma_{u}^{2}}{2}}\left(\frac{\sqrt{\sigma_{\varepsilon}^{2}+(1-\gamma) \sigma_{v}^{2}}}{2\left(\sigma_{v}^{2}+\sigma_{\varepsilon}^{2}\right)+(1-\gamma) \sigma_{v}^{2}}\right)
$$

from their investments into fund $i \in\{1,2\}$.

And, we can easily prove the following results.

Corollary 2 Investors are worse off the higher the relative performance pay component is.

Proof. See Appendix.

Furthermore, in the terminology of Kyle (1985), we know that the depth of the market can be represented as $\frac{1}{\lambda}$, and that price informativeness is a decreasing function of $\operatorname{Var}[v \mid P]$. Then, as another corollary to Proposition 1, we have:

Corollary 3 If the importance of relative performance on fund managers pay is increased:

(i) Liquidity of the markets increases;

(ii) The information content of prices increases;

(iii) Adverse selection costs faced by noise (liquidity) traders decrease;

(iv) Trading aggressiveness of fund managers increases.

Proof. See Appendix.

To summarize, the adoption of relative performance contracts has positive and negative effects. Investors are worse off ${ }^{12}$ but markets function better, under free information acquisition. In the next section we show that some of these, apparent, positive effects of relative performance may disappear once we endogeneize the decision to become informed. But, before we move on, we present the results for multiple assets/markets, analyzing the possibility of cross-market contagion and volatility effects.

\footnotetext{
${ }^{12}$ We show later that fund managers are worse off as well.
} 


\section{III.2 Multiple Markets}

Here we extend the model to allow for multiple assets and markets. First, we analyze the effects of fulcrum fees on cross-market correlations. Then we look at the effect of including a stock in the benchmark.

\section{III.2.1 Cross-Market Correlation}

Suppose there are two separate markets for two distinct assets. Each market maintains the structure discussed in Section II, and they are separated by the assumption that each pair of funds trades in only one of them. Each fund is benchmarked only against the other fund that trades in the same market, and each market has a potentially different $\gamma \cdot{ }^{13}$ We assume, without loss of generality, that funds 1 and 2 trade on asset/market 1, and that funds 3 and 4 trade on asset/market 2 . We let $\gamma_{m}$ be the relative performance parameter for each market $m=1,2$. Furthermore, each market maker observes only the aggregate order flow of his own market. This is an important assumption because we assume that the assets' payoffs are correlated, therefore order flow in one market offers information about the payoff of the asset traded in the other market. So, there are two risky assets with final payoffs given by

$$
\widetilde{v}_{m} \sim N\left(0, \sigma_{m}^{2}\right)
$$

and signals given by

$$
\widetilde{s}_{i m}=\widetilde{v}_{m}+\widetilde{\varepsilon}_{i m}, i m=11,21,32,42
$$

where $m$ index markets/assets and $i$ index managers, with the understanding that managers 1 and 2 trade in the market for asset 1, and managers 3 and 4 trade on asset 2 . We also assume that signals have the same precision, so that $\operatorname{Var}\left(\widetilde{\varepsilon}_{i m}\right)=\sigma_{\varepsilon m}^{2}$, and liquidity trades are given by $\widetilde{u}_{m} \sim$

\footnotetext{
${ }^{13}$ This assumption would be justified if the chosen benchmarks reflect the characteristics or "style" of a fund. This is indeed the case in a theoretical setting (e.g., Ou-Yang (2003)), but it is also true, at least to a certain extent, in practice as most funds use a market index (such as the S\&P 500 or Russell) that is adjusted on size and value/growth dimensions to the fund's characteristics (Sensoy (2009)). Note that in an international setting the use of domestic benchmarks, i.e., performance of those trading in the same market, would also be justified by the potentially higher costs faced by investors if they choose a foreign fund over a domestic one, perhaps due to cross-border differences in regulations and institutional and legal frameworks.
} 
$N\left(0, \sigma_{u m}^{2}\right)$. Finally, we assume that all random variables are normally distributed and independent of each other, with the exception of $\widetilde{v}_{1}$ and $\widetilde{v}_{2}$, where we assume that $\operatorname{Cov}\left(\widetilde{v}_{1}, \widetilde{v}_{2}\right)=\sigma_{12}^{v}>0$.

Given this structure, it is clear that the issue at hand is not one of contagion per se. We do not investigate the question of appearance of correlation across assets that are otherwise uncorrelated. The objective is to analyze the marginal effect of relative performance contracts on cross-market correlation. Even if $\gamma_{m}=0, \forall m$, we would have correlated prices, because payoffs are correlated. With the correlation recognized, we show how the presence of such contracts may enhance this correlation.

Proposition 2 With the described set-up for each market we have that

$$
P_{m}=\lambda_{m}\left(\alpha_{1 m}+\alpha_{2 m}+u_{m}\right) \quad \text { and } \alpha_{i m}=\beta_{m} \widetilde{s}_{i m}
$$

where

$$
\beta_{m}=\sqrt{\frac{\sigma_{u m}^{2}}{2\left(1-\gamma_{m}\right) \sigma_{m}^{2}+2 \sigma_{\varepsilon m}^{2}}} \text { and } \lambda_{m}=\frac{2 \sigma_{m}^{2} \sqrt{\frac{\sigma_{u m}^{2}}{2\left(1-\gamma_{m}\right) \sigma_{m}^{2}+2 \sigma_{\varepsilon m}^{2}}}}{\left(2 \sigma_{m}^{2}+\sigma_{\varepsilon m}^{2}\right) \frac{\sigma_{u m}^{2}}{\left(1-\gamma_{m}\right) \sigma_{m}^{2}+\sigma_{\varepsilon m}^{2}}+\sigma_{u m}^{2}}
$$

characterizes a linear symmetric equilibrium in each market $m$. Given this characterization, we can calculate the correlation between $P_{1}$ and $P_{2}$ to be equal to

$$
\rho=\frac{4 \beta_{1} \beta_{2} \sigma_{12}^{v}}{\sqrt{\left(4 \beta_{1}^{2} \sigma_{1}^{2}+2 \beta_{1}^{2} \sigma_{\varepsilon 1}^{2}+\sigma_{u 1}^{2}\right)\left(4 \beta_{2}^{2} \sigma_{2}^{2}+2 \beta_{2}^{2} \sigma_{\varepsilon 2}^{2}+\sigma_{u 2}^{2}\right)}} .
$$

And,

$$
\frac{\partial \rho}{\partial \gamma_{m}}>0, \forall m
$$

Proof. See Appendix.

This proposition shows that the presence of relative performance contracts may enhance correlation between markets. We observe more correlated prices whenever at least one of the markets has funds with relative performance contracts. This result does not depend on the assumption that both markets have relative performance contracts. It is enough that one of the markets has this type of contract. Then, if the importance of relative performance is increased in such a market, the correlation across markets increase. The intuition for this result comes, again, from the fact that aggressiveness increases with relative performance. An increase in the aggressiveness with which 
traders use their signals leads prices to reflect these signals more prominently. Since the signals are functions of the correlated final values, the importance of this correlation increases, leading to more correlated prices.

\section{III.2.2 Benchmark Inclusion}

Next we consider a slightly modified version of the model. As before, there are two risky assets with final payoffs given by (10) but with $\operatorname{Cov}\left(\widetilde{v}_{1}, \widetilde{v}_{2}\right)=0$. Furthermore, assume that we have two funds, both trading on these assets, and let each manager have perfect signals about both assets, $\widetilde{\varepsilon}_{i m} \equiv 0$. So, we have two independent assets that are traded by two funds. (Previously, we have considered one asset traded by two funds, and then two assets each of which is traded by both funds). This generalization naturally leads us to re-define manager $i$ 's objective as

$$
\max _{\alpha_{i 1}, \alpha_{i 2}} \mathbb{E}\left\{\phi\left[\alpha_{i 1}\left(v_{1}-P_{1}\right)+\alpha_{i 2}\left(v_{2}-P_{2}\right)-\gamma_{1} \alpha_{j 1}\left(v_{1}-P_{1}\right)-\gamma_{2} \alpha_{j 2}\left(v_{2}-P_{2}\right)\right] \mid v_{1}, v_{2}\right\}
$$

Since we have independent assets, we can re-write this objective as

$$
\max _{\alpha_{i 1}} \mathbb{E}\left\{\phi\left[\alpha_{i 1}\left(v_{1}-P_{1}\right)-\gamma_{1} \alpha_{j 1}\left(v_{1}-P_{1}\right)\right] \mid v_{1}\right\}+\max _{\alpha_{i 2}} \mathbb{E}\left\{\phi\left[\alpha_{i 2}\left(v_{2}-P_{2}\right)-\gamma_{2} \alpha_{j 2}\left(v_{2}-P_{2}\right)\right] \mid v_{2}\right\}
$$

The parameter $\gamma_{m}$ is meant to capture the importance of asset $m$ in the benchmark. An example where different $\gamma_{m}$ may arise is the case where one asset is listed in the S\&P 500 and the other is not. Or, alternatively, an asset may be domestic while the other may be foreign. With independent liquidity trades, $u_{m}$, we can solve the problem for each asset separately and obtain

$$
P_{m}=\lambda_{m}\left(\alpha_{1 m}+\alpha_{2 m}+u_{m}\right), m=1,2 \text { and } \alpha_{i m}=\beta_{m} \widetilde{s}_{i m}, i=1,2
$$

with

$$
\beta_{m}=\sqrt{\frac{\sigma_{u m}^{2}}{2\left(1-\gamma_{m}\right) \sigma_{m}^{2}}} \text { and } \lambda_{m}=\frac{\sqrt{\frac{2\left(1-\gamma_{m}\right) \sigma_{m}^{2}}{\sigma_{u m}^{2}}}}{\left(3-\gamma_{m}\right)} \text {. }
$$

Hence,

$$
\operatorname{Var}\left(P_{m}\right)=\left(\lambda_{m}\right)^{2}\left[4 \sigma_{m}^{2}\left(\beta_{m}\right)^{2}+\sigma_{u m}^{2}\right]=\frac{4 \sigma_{m}^{2}}{\left(3-\gamma_{m}\right)^{2}}+\frac{2\left(1-\gamma_{m}\right) \sigma_{m}^{2}}{\left(3-\gamma_{m}\right)^{2}}=\frac{2 \sigma_{m}^{2}}{3-\gamma_{m}}
$$


We consider a stock $m$ to be included in the benchmark iff $\gamma_{m}>0$. Notice that, if $\gamma_{m}=0$, then $\operatorname{Var}\left(P_{m}\right)=\frac{2}{3} \sigma_{m}^{2}<\frac{2 \sigma_{m}^{2}}{3-\gamma_{m}}$. Therefore, when a stock is not included in the benchmark, $\gamma_{m}=0$, it has a smaller price volatility than when it is included. So, inclusion raises volatility. Furthermore, the more heavily the compensation package relies on a stock (higher $\gamma_{m}$ ), the higher the variance

of that stock price, i.e., $\frac{\partial \operatorname{Var}\left(P_{m}\right)}{\partial \gamma_{m}}>0$. This result is similar to the one obtained by Cuoco and Kaniel (2011), albeit in a different market microstructure.

\section{III.2.3 Home Bias with Exogenous Benchmark}

Now, once again, we change the framework of our model slightly to explore yet another effect of relative performance: home bias. We assume that, instead of having two funds each indexed against the other, we have one fund indexed against a given exogenous benchmark (for instance, the S\&P 500). So, we have two assets each with final value given by

$$
\widetilde{v}_{m} \sim N\left(0, \sigma_{m}^{2}\right), m=1,2
$$

and signals given by

$$
\widetilde{s}_{m}=\widetilde{v}_{m}
$$

where $m$ index assets and there is only one fund manager. We also assume that liquidity trades are given by $\widetilde{u}_{m} \sim N\left(0, \sigma_{u m}^{2}\right)$ and are independent of each other and of the assets' final value.

Finally, we assume that the fund manager's expected payoff is given by

$$
\mathbb{E}\left\{\psi(v-P) D^{T}+\lambda\left[(v-P) D^{T}-\gamma(v-P) D_{B}^{T}\right]\right\},
$$

where

$$
v=\left(\begin{array}{l}
v_{1} \\
v_{2}
\end{array}\right), P=\left(\begin{array}{c}
P_{1} \\
P_{2}
\end{array}\right), D=\left(\begin{array}{c}
\alpha_{1} \\
\alpha_{2}
\end{array}\right), D_{B}=\left(\begin{array}{c}
w_{1} \\
w_{2}
\end{array}\right)
$$

and $w_{i}$ is the weight of asset $i$ on the exogenous benchmark (for instance, the participation of the stock on the S\&P 500).

By solving the model in the same way as before, we have

$$
\begin{aligned}
& \alpha_{m}=\beta_{m} v_{m}+A_{m}, \\
& P_{m}=\lambda_{m}\left(\alpha_{m}+u_{m}\right),
\end{aligned}
$$


for $m=1,2$ and

$$
\beta_{m}=\frac{(\psi+\lambda)}{2 \lambda_{m}}, A_{m}=\frac{\lambda \gamma w_{m}}{2}, \lambda_{m}=\frac{\beta_{m}}{\beta_{m}^{2} \sigma_{m}^{2}+\sigma_{u m}^{2}} .
$$

And, if we concentrate in a situation similar to the ones discussed in the previous sections by imposing $\psi+\lambda=1$, we have that

$$
\alpha_{m}=\left(\sqrt{\frac{1}{2} \frac{\sigma_{u m}^{2}}{\sigma_{m}^{2}}}\right) v_{m}+\frac{\lambda \gamma w_{m}}{2}>\left(\sqrt{\frac{1}{2} \frac{\sigma_{u m}^{2}}{\sigma_{m}^{2}}}\right) v_{m}=\alpha_{m}^{K y l e},
$$

where the last term is the traditional demand in this setting without relative performance pay (see Kyle (1985)). Therefore, we see that, if funds are benchmarked against an exogenous index, demand for asset $m$ increases with $w_{m}$.

If we think about asset 1 as domestic and asset 2 as foreign and assume that domestic funds are benchmarked against domestic assets only $\left(w_{2}=0\right)$, we see that these funds will be overexposed to domestic assets: $\alpha_{m}>\alpha_{1}^{K y l e}$. This result provides an alternative explanation for the widelydocumented home bias phenomenon, i.e., the observation that investors tend to favor local stocks, both in an international (e.g., Tesar and Werner (1995)) and domestic setting (e.g., Coval and Moskowitz (1999)). ${ }^{14,15}$

\section{Information Acquisition}

Next, we revert back to the single asset framework, but assume that fund managers may or may not acquire costly information. Let $c$ denote the information acquisition cost. If no information is acquired, the manager stays out of the market. This is because uninformed trading is nonprofitable. We start with a simple case where both managers have access to the information or not - either both are informed or both are uninformed. Then we analyze the more interesting case where each manager decides independently whether to acquire information or not.

\footnotetext{
${ }^{14}$ Another form of home bias has been documented in that employees tend to hold excessive amounts of own company stock in their retirement saving plans (e.g., Benartzi and Thaler (2001)). Pinheiro (2008) provides a rational explanation for this seemingly suboptimal exposure based on social interactions.

${ }^{15}$ Most explanations for home bias rely either on impediments to trade due to institutional, legal, and regulatory frameworks or on some form of residence-based assymmetric information.
} 


\section{IV.1 Information as a Public Good}

If both managers either have access to the information or not, calculating manager $i$ 's profit if both decide to be informed is straightforward and leads to the following.

Proposition 3 Each manager expects to be paid

$$
\mathbb{E} \phi\left[\left(\alpha_{i}-\gamma \alpha_{j}\right)(v-P)\right]=\phi(1-\gamma) \beta \sigma_{v}^{2}\left[\frac{\sigma_{\varepsilon}^{2}+(1-\gamma) \sigma_{v}^{2}}{2\left(\sigma_{v}^{2}+\sigma_{\varepsilon}^{2}\right)+(1-\gamma) \sigma_{v}^{2}}\right]
$$

And,

$$
\frac{d}{d \gamma} \mathbb{E} \phi\left[\left(\alpha_{i}-\gamma \alpha_{j}\right)(v-P)\right]<0
$$

Therefore, fund managers' pay is decreasing on the relative performance parameter. Furthermore, if there exists a $\bar{\gamma}$ such that

$$
\mathbb{E} \phi\left[\left(\alpha_{i}-\bar{\gamma} \alpha_{j}\right)(v-P)\right]=c,
$$

then for any $\gamma>\bar{\gamma}$ no information is acquired.

Proof. See Appendix.

The above proposition shows that not only investors are worse off but also the managers themselves. More importantly, given the cost of signals, it may be the case that for high enough $\gamma$ no information is acquired. While it may come as a surprise at a first glance, this is an intuitive result: Profits are decreasing in $\gamma$, so if there is a point where the managers are just indifferent between acquiring information or not, then, for any higher $\gamma$ they will prefer to be uninformed and save $c$.

In summary, conditional on the information being acquired, prices are more informative (as described in Section III), but it may be the case that no information is acquired at all, rendering the earlier point on the information content of prices moot.

To enhance our understanding of these countervailing effects, we further assume that the cost of information acquisition is randomly drawn from a distribution $F($.$) , common to both managers.$ The cost is drawn once from this distribution and represents the cost for each manager. Based on the analysis so far, we know that the managers will acquire information with probability

$$
F\left(\mathbb{E} \phi\left[\left(\alpha_{i}-\gamma \alpha_{j}\right)(v-P)\right]\right)
$$


i.e., if $\widetilde{c}<\mathbb{E} \phi\left[\left(\alpha_{i}-\gamma \alpha_{j}\right)(v-P)\right]$.

We can then calculate the expected price response to trades, i.e., $\mathbb{E} \lambda(\gamma)$ :

$$
F\left(\mathbb{E} \phi\left[\left(\alpha_{i}-\gamma \alpha_{j}\right)(v-P)\right]\right) \frac{2 \sigma_{v}^{2} \sqrt{\frac{\sigma_{u}^{2}}{2(1-\gamma) \sigma_{v}^{2}+2 \sigma_{\varepsilon}^{2}}}}{\left(2 \sigma_{v}^{2}+\sigma_{\varepsilon}^{2}\right) \frac{\sigma_{u}^{2}}{(1-\gamma) \sigma_{v}^{2}+\sigma_{\varepsilon}^{2}}+\sigma_{u}^{2}}+\left[1-F\left(\mathbb{E} \phi\left[\left(\alpha_{i}-\gamma \alpha_{j}\right)(v-P)\right]\right)\right] \times 0 .
$$

Hence,

$$
\frac{d}{d \gamma} \mathbb{E} \lambda(\gamma)=\lambda(\gamma)\left[\frac{d}{d \gamma} F\left(\mathbb{E} \phi\left[\left(\alpha_{i}-\gamma \alpha_{j}\right)(v-P)\right]\right)\right]+\left[\frac{d}{d \gamma} \lambda(\gamma)\right] F\left(\mathbb{E} \phi\left[\left(\alpha_{i}-\gamma \alpha_{j}\right)(v-P)\right]\right)<0
$$

where the inequality follows from the fact that

$$
\frac{d}{d \gamma} F\left(\mathbb{E} \phi\left[\left(\alpha_{i}-\gamma \alpha_{j}\right)(v-P)\right]\right)<0
$$

as argued before, and $\frac{d}{d \gamma} \lambda(\gamma)<0$, as proved in Corollary 3 .

This result shows that the expected price response to order flow decreases as $\gamma$ increases. This would indicate that markets are more liquid, even when there is an additional information acquisition stage. However, if we were to measure the depth of the market, the usual measure of liquidity in this framework, we would run into problems. Depth is given by $\frac{1}{\lambda}$, which is undefined (goes to infinity) if there are no informed traders in the market. Hence, as long as there is a strictly positive probability of no information collection, depth would be independent of $\gamma$. And, the market would have an infinite expected depth. Therefore, we concentrate on the former measure to claim that markets are more liquid with relative performance, even in the presence of information acquisition stage. Notice that this result is independent of $F($.$) .$ 
We can also measure the expected informational content of prices. This can be shown to be inversely related to ${ }^{16}$

$$
\sigma_{v}^{2}\left(1-F\left(\mathbb{E} \phi\left[\left(\alpha_{i}-\gamma \alpha_{j}\right)(v-P)\right]\right)\left[\frac{4 \beta^{2} \sigma_{v}^{2}}{4 \beta^{2} \sigma_{v}^{2}+2 \beta^{2} \sigma_{\varepsilon}^{2}+\sigma_{u}^{2}}\right]\right)
$$

And, differentiating the above expression with respect to $\gamma$ reveals

$$
\begin{aligned}
& \frac{d\left[F\left(\mathbb{E} \phi\left[\left(\alpha_{i}-\gamma \alpha_{j}\right)(v-P)\right]\right)\right]}{d \gamma}\left[\frac{-4 \beta^{2} \sigma_{v}^{4}}{4 \beta^{2} \sigma_{v}^{2}+2 \beta^{2} \sigma_{\varepsilon}^{2}+\sigma_{u}^{2}}\right] \\
&-F\left(\mathbb{E} \phi\left[\left(\alpha_{i}-\gamma \alpha_{j}\right)(v-P)\right]\right)\left[\frac{\sigma_{v}^{2}}{4 \beta^{2} \sigma_{v}^{2}+2 \beta^{2} \sigma_{\varepsilon}^{2}+\sigma_{u}^{2}}\right]^{2} 8 \beta \sigma_{u}^{2} \frac{d \beta}{d \gamma} .
\end{aligned}
$$

The first term is the product of two negative terms, hence positive. The last term is the product of two terms with opposite signs, hence negative. The overall sign of the expression cannot be determined. The first term represents the fact that there is less chance of obtaining more informative prices and less information acquisition. The second term represents the effect that, if information is acquired, prices will be more informative. The overall effect is indeterminate.

In order to determine the sign of this expression subject to certain circumstances, we further simplify our model. The assumptions and results are spelled out in the following proposition.

Proposition 4 Assume that the distribution of costs is uniform on $[0, \bar{c}]$, with

$$
\bar{c}>\phi \frac{\sqrt{(1-\gamma)^{3}}}{3-\gamma} \sqrt{\frac{\sigma_{u}^{2} \sigma_{v}^{2}}{2}} .
$$

And, furthermore, set $\widetilde{\varepsilon}_{i} \equiv 0$. Then, the expected informational content of prices is decreasing in $\gamma$, i.e., expression (30) is positive, so that the expected conditional variance of prices increases with $\gamma$

${ }^{16}$ Note that this is no longer $\operatorname{Var}(v \mid P)$. This is just the expected value of the conditional variance of $v$, conditional on whether or not there was information acquisition. Since $P$ now is a mixed random variable, no longer normal, calculation of $\operatorname{Var}(v \mid P)$ would be very elaborate. And, we adopt this short-cut measure just to grasp the idea of the countervailing effects at play. The true value for it is obtained by adding to the expression in the text the following term

$$
F\left(\mathbb{E} \phi\left[\left(\alpha_{i}-\gamma \alpha_{j}\right)(v-P)\right]\right)\left[1-F\left(\mathbb{E} \phi\left[\left(\alpha_{i}-\gamma \alpha_{j}\right)(v-P)\right]\right)\right] \frac{2 \lambda \beta \sigma_{v}^{2}\left[\lambda\left(\beta \widetilde{s_{1}}+\beta \widetilde{s_{2}}+\widetilde{u}\right)\right]}{\lambda^{2}\left(4 \beta^{2} \sigma_{v}^{2}+2 \beta^{2} \sigma_{\varepsilon}^{2}+\sigma_{u}^{2}\right)},
$$

making it even messier, and, now, dependent of the realization of random variables. Note that this term has zero expected value. Therefore, the expression in the main text is just the expected value of the conditional variance. 


\section{Proof. See Appendix.}

This proposition shows that, with some additional restrictions, the result that price informativeness increases with $\gamma$ is reversed. The effect of less information acquisition dominates the effect that, conditional on information acquisition, prices are more informative. So, higher $\gamma$ leads to less informative prices ex-ante.

In summary, either with free information or costly public information, our model delivers that markets are deeper, the more important the relative performance objective is (lower $\mathbb{E} \lambda(\gamma)$ ). However, costly information, even public, may lead to less informative prices (e.g., under uniform distribution of costs). The intuition for the first result is clear: The depth of the market is inversely related to the information asymmetry problem, so less information acquisition cannot, in the current framework, decrease depth. The second result is a direct consequence of the decrease in the probability of information acquisition.

\section{IV.2 Information as a Private Good}

We now move to a more interesting informational structure. Suppose that each manager may or may not be informed. In other words, there are three possible outcomes: two informed managers, one informed and one uninformed, and both uninformed. For this part of the analysis, we again consider the case where agents have perfect information if they decide to be informed, i.e., we set $\varepsilon_{i} \equiv 0$.

First suppose that both managers are informed. Then each has an expected profit of

$$
\mathbb{E} \phi\left[\left(\alpha_{i}-\gamma \alpha_{j}\right)(v-P)\right]=\phi \frac{\sqrt{(1-\gamma)^{3}}}{3-\gamma} \sqrt{\frac{\sigma_{u}^{2} \sigma_{v}^{2}}{2}} .
$$

If only one is informed, we are in the exact framework of Kyle (1985), $\gamma$ is irrelevant, and we know that the informed fund manager makes

$$
\mathbb{E} \phi\left[\alpha_{i}(v-P)\right]=\phi \frac{\sqrt{\sigma_{u}^{2} \sigma_{v}^{2}}}{2}
$$

while the uninformed has zero expected profit. Finally, in the case of two uninformed managers, both have zero expected profits. 
Notice that

$$
\mathbb{E} \phi\left[\alpha_{i}(v-P)\right]>\mathbb{E} \phi\left[\left(\alpha_{i}-\gamma \alpha_{j}\right)(v-P)\right],
$$

if and only if $\frac{\sqrt{(1-\gamma)^{3}}}{3-\gamma} \sqrt{2}<1, \forall \gamma$. Furthermore,

$$
\frac{\partial}{\partial \gamma}\left(\frac{\sqrt{(1-\gamma)^{3}}}{3-\gamma} \sqrt{2}\right)<0
$$

and

$$
\left.\left(\frac{\sqrt{(1-\gamma)^{3}}}{3-\gamma} \sqrt{2}\right)\right|_{\gamma=0}=\frac{\sqrt{2}}{3}<1
$$

Therefore, the required inequality holds for all $\gamma$, as expected, since managers' profits are decreasing in $\gamma$. The following proposition summarizes the insight from this reasoning.

Proposition 5 In the information acquisition stage, there are three possible equilibrium outcomes, depending on the realization of $c$ :

(i) If $c>\phi \frac{\sqrt{\sigma_{u}^{2} \sigma_{v}^{2}}}{2}$, the market cannot support any informed traders, and the managers are both better off not acquiring information and staying out;

(ii) If $\phi \frac{\sqrt{\sigma_{u}^{2} \sigma_{v}^{2}}}{2}>c>\phi \frac{\sqrt{(1-\gamma)^{3}}}{3-\gamma} \sqrt{\frac{\sigma_{u}^{2} \sigma_{v}^{2}}{2}}$, then the market can support one informed agent, but not two;

(iii) Finally, if $\phi \frac{\sqrt{(1-\gamma)^{3}}}{3-\gamma} \sqrt{\frac{\sigma_{u}^{2} \sigma_{v}^{2}}{2}}>c$, the market supports two informed agents.

Now, the measure of the expected informational content of prices is inversely related to

$$
F\left(\phi \frac{\sqrt{(1-\gamma)^{3}}}{3-\gamma} \sqrt{\frac{\sigma_{u}^{2} \sigma_{v}^{2}}{2}}\right)\left(\frac{\sigma_{u}^{2} \sigma_{v}^{2}}{4 \beta^{2} \sigma_{v}^{2}+\sigma_{u}^{2}}-\frac{\sigma_{v}^{2}}{2}\right)-F\left(\phi \frac{\sqrt{\sigma_{u}^{2} \sigma_{v}^{2}}}{2}\right) \frac{\sigma_{v}^{2}}{2}+\sigma_{v}^{2}
$$

or,

$$
F\left(\phi \frac{\sqrt{(1-\gamma)^{3}}}{3-\gamma} \sqrt{\frac{\sigma_{u}^{2} \sigma_{v}^{2}}{2}}\right)\left(\frac{\frac{\sigma_{u}^{2} \sigma_{v}^{2}}{2}-2 \beta^{2} \sigma_{v}^{4}}{4 \beta^{2} \sigma_{v}^{2}+\sigma_{u}^{2}}\right)-F\left(\phi \frac{\sqrt{\sigma_{u}^{2} \sigma_{v}^{2}}}{2}\right) \frac{\sigma_{v}^{2}}{2}+\sigma_{v}^{2} .
$$

And, again the derivative

$$
\left(\frac{\frac{\sigma_{u}^{2} \sigma_{v}^{2}}{2}-2 \beta^{2} \sigma_{v}^{4}}{4 \beta^{2} \sigma_{v}^{2}+\sigma_{u}^{2}}\right) \frac{d}{d \gamma} F\left(\phi \frac{\sqrt{(1-\gamma)^{3}}}{3-\gamma} \sqrt{\frac{\sigma_{u}^{2} \sigma_{v}^{2}}{2}}\right)+F\left(\phi \frac{\sqrt{(1-\gamma)^{3}}}{3-\gamma} \sqrt{\frac{\sigma_{u}^{2} \sigma_{v}^{2}}{2}}\right) \frac{d}{d \gamma}\left(\frac{\frac{\sigma_{u}^{2} \sigma_{v}^{2}}{2}-2 \beta^{2} \sigma_{v}^{4}}{4 \beta^{2} \sigma_{v}^{2}+\sigma_{u}^{2}}\right)
$$


cannot be signed, since the first term is positive (product of two negative terms), and the second is negative (product of terms with opposing signs).

We can also analyze the expected price response to trades, i.e., $\mathbb{E} \lambda(\gamma)$ :

$$
F\left(\phi \frac{\sqrt{(1-\gamma)^{3}}}{3-\gamma} \sqrt{\frac{\sigma_{u}^{2} \sigma_{v}^{2}}{2}}\right) \frac{2 \sigma_{v}^{2} \sqrt{\frac{\sigma_{u}^{2}}{2(1-\gamma) \sigma_{v}^{2}}}}{2 \frac{\sigma_{u}^{2}}{(1-\gamma)}+\sigma_{u}^{2}}+\left[F\left(\phi \frac{\sqrt{\sigma_{u}^{2} \sigma_{v}^{2}}}{2}\right)-F\left(\phi \frac{\sqrt{(1-\gamma)^{3}}}{3-\gamma} \sqrt{\frac{\sigma_{u}^{2} \sigma_{v}^{2}}{2}}\right)\right] \frac{\sigma_{v}^{2}}{2 \sigma_{u}^{2}},
$$

or

$$
F\left(\phi \frac{\sqrt{(1-\gamma)^{3}}}{3-\gamma} \sqrt{\frac{\sigma_{u}^{2} \sigma_{v}^{2}}{2}}\right)\left[\frac{2 \sigma_{v}^{2} \sqrt{\frac{\sigma_{u}^{2}}{2(1-\gamma) \sigma_{v}^{2}}}}{\frac{(3-\gamma) \sigma_{u}^{2}}{(1-\gamma)}}-\frac{\sigma_{v}^{2}}{2 \sigma_{u}^{2}}\right]+F\left(\phi \frac{\sqrt{\sigma_{u}^{2} \sigma_{v}^{2}}}{2}\right) \frac{\sigma_{v}^{2}}{2 \sigma_{u}^{2}},
$$

and calculating derivatives

$$
\begin{gathered}
{\left[\frac{\left.4 \sigma_{v}^{2} \sqrt{\frac{\sigma_{u}^{2}}{2(1-\gamma) \sigma_{v}^{2}}}-\frac{(3-\gamma) \sigma_{v}^{2}}{(1-\gamma)}\right]}{\sigma_{u}^{2} \frac{(3-\gamma) 2}{(1-\gamma)}}\right] \frac{d F\left(\frac{\phi \sqrt{(1-\gamma)^{3}} \sqrt{\frac{\sigma_{u}^{2} \sigma_{v}^{2}}{2}}}{3-\gamma}\right)}{d \gamma}} \\
+F\left(\frac{\phi \sqrt{(1-\gamma)^{3}} \sqrt{\frac{\sigma_{u}^{2} \sigma_{v}^{2}}{2}}}{3-\gamma}\right) \frac{d\left[\frac{4 \sigma_{v}^{2} \sqrt{\frac{\sigma_{u}^{2}}{2(1-\gamma) \sigma_{v}^{2}}}-\frac{(3-\gamma) \sigma_{v}^{2}}{(1-\gamma)}}{\sigma_{u}^{2} \frac{(3-\gamma) 2}{(1-\gamma)}}\right]}{d \gamma} .
\end{gathered}
$$

But, now we cannot sign this expression, as we do not know the sign of $\left[\frac{4 \sigma_{v}^{2} \sqrt{\frac{\sigma_{u}^{2}}{2(1-\gamma) \sigma_{v}^{2}}-\frac{(3-\gamma) \sigma_{v}^{2}}{(1-\gamma)}}}{\sigma_{u}^{2} \frac{(3-\gamma) 2}{(1-\gamma)}}\right]$. So when we add discretionary information acquisition as described here, we cannot determine what happens to the expected liquidity of the market as relative performance objectives become more important. The term in square brackets is the difference between price responses in a market with two traders and price responses in a market with one trader, i.e., $\lambda_{2 \text { Trader }}(\gamma)-\lambda_{1 \text { Trader }}$. This expression depends on the parameter values and, often, it changes sign as $\gamma$ varies.

Unfortunately, the inconclusiveness of both results remains even if we assume that costs are uniformly distributed, as before. The only thing that can undoubtedly be stated is that information acquisition is ex-ante hindered by the presence of relative performance objectives. If we increase $\gamma$, then some values of $c$ that support equilibria with two informed agents may no longer do so. Increase in $\gamma$ leads to an increase in the length of the cost interval where only one informed agent can be supported in equilibrium, and a decrease in the length of the cost interval where two informed 
agents can co-exist.

To shed some more light in the discussion, we resort to numerical analysis, under the assumption that costs are uniformly distributed on the unit interval. We concentrate on the typical behavior of the market microstructure elements that obtain indeterminate derivative signs in the analytical solutions.

First, we look at the informational content of prices. Figure 1 presents the typical relationship between the expected conditional variance of prices and the measure of relative performance, $\gamma$. As with the case of public information, we obtain that this variance is an increasing function of $\gamma$, hence, as before, prices become less informative as relative performance objectives increase in importance. After a large number of simulations, the conclusion emerges to be that this result is pervasive and does not seem to depend on the parameter values. So, costly information, private or public, is enough to reverse the positive effects of relative performance on price informativeness.

Second, we take a closer look at the expected price responses to trades analyzing $\mathbb{E} \lambda(\gamma)$, a measure inversely related to depth. Note that the behavior of this function depends on the difference $\lambda_{2 \text { Trader }}(\gamma)-\lambda_{1 \text { Trader }}$. If this difference is positive, less information acquisition is always good: moving from two to one trader, or one to zero, increases depth. This is a situation similar to the one under public information. Now, if this difference is negative, then less information acquisition may be bad: moving from two to one trader decreases depth but moving from one to zero traders still increases depth. Notice that as $\gamma \rightarrow 1, \lambda_{2 \text { Trader }}(\gamma) \rightarrow 0$ so that for high enough $\gamma$ the difference is negative. Furthermore, whenever $2 \sqrt{2}<\frac{3-\gamma}{\sqrt{(1-\gamma)}} \sqrt{\frac{\sigma_{v}^{2}}{\sigma_{u}^{2}}}$, the difference is also negative. So, apart from $\gamma$, the ratio $\sqrt{\frac{\sigma_{v}^{2}}{\sigma_{u}^{2}}}$ plays an important role in determining the sign of this expression. In summary, the behavior of the expected price responses to trades as a function of $\gamma$ can take three possible shapes. We visually depict these three possible situations below. In Figure 2, we have an always decreasing price response to trades, indicating an increase in depth. Figure 3 shows a case where the price response is decreasing at the beginning and reverses as $\gamma$ grows, implying that less information acquisition becomes bad because $\lambda_{2 \text { Trader }}(\gamma)-\lambda_{1 \text { Trader }}<0$. Finally, Figure 4 depicts a case where the price response is always increasing, reflecting the fact that the effect of less information acquisition is dominating and negative. 
The shape depicted in Figure 2 is obtained whenever we have a low value for $\sqrt{\frac{\sigma_{v}^{2}}{\sigma_{u}^{2}}}$, so that $\lambda_{2 \text { Trader }}(\gamma)-\lambda_{1 \text { Trader }}>0$ and less information helps the depth of the market. Toward the end, the relationship flattens since $\gamma \rightarrow 1$. The shape shown in Figure 3 is obtained for higher values

of the ratio $\frac{\sigma_{v}^{2}}{\sigma_{u}^{2}}$. The reversal sets in because, as $\gamma$ increases, less information acquisition hurts the depth of the market (going from two to one trader is bad), and this effect dominates when $\gamma$ is high enough. The shape illustrated in Figure 4 is obtained when we start with a very high value of $\frac{\sigma_{v}^{2}}{\sigma_{u}^{2}}$ so that moving from two to one trader is always bad, i.e., it decreases depth.

The numerical results for the price informativeness confirm the analytical results obtained with public information. Relative performance decreases price informativeness when information is costly. However, the results for the depth of the market can be quite different depending on parameter values. The main insight here is that information acquisition can help increase market depth, even though it increases information asymmetry, and there exists parameter values for which information acquisition would only decrease market depth.

In summary, our theoretical results predict that relative performance always increases market depth except under private costly information and some additional restriction on the parameters. However, we can only say with confidence that relative performance increases price informativeness under free information. Under costly information, this result may be easily reversed and it is always reversed under private costly information.

\section{Conclusion}

In this paper, we analyze the potential effects of the adoption of relative performance pay for fund managers. We show that, if fund managers are rewarded based on a relative performance measure, there can be deleterious effects for investors translating into a lower expected utility. However, markets will typically be more informative and deeper, if information is free.

When we endogeneize the acquisition of information, we see that incentives to acquire information may be hindered by relative performance contracts. This last effect may, ex-ante, reduce the informativeness and depth of the market. So, even though conditional on information being acquired markets function "better", less information acquisition acts in a countervailing way. In 
other words, the result that prices are more informative holds only for the case of free information, it is reversed when information is costly. The result that markets are deeper (more liquid) also holds for the case of free information and for public costly information and may or may not hold in the case of private costly information.

These findings as a whole point to the need for a more nuanced understanding of the contracts that aim to solve the agency problem between managers and investors. Especially from a regulator's perspective, there can be a trade-off between the benefits of aligning the principal's interests with those of the agent and the potential costs associated with the effects on contagion, volatility, and the informativeness of markets. How this trade-off can be dealt with is a direction for future research. 


\section{References}

[1] Admati, A.R., and P. Pfleiderer (1997). "Does It All Add Up? Benchmarks and the Compensation of Active Portfolio Managers," Journal of Business 70, 323-350.

[2] Bagnoli, M., and S. Watts (2000). "Chasing Hot Funds: The Effects of Relative Performance on Portfolio Choice," Financial Management 29 (3), 31-50.

[3] Benartzi, S., and R. Thaler (2001). "Naive Diversification Strategies in Retirement Saving Plans," American Economic Review 91, 79-98.

[4] Berk, J. B., and R. C. Green (2004). "Mutual Fund Flows and Performance in Rational Markets," Journal of Political Economy 112 (6), 1269-1295.

[5] Broner, F. A., R. G. Gelos, and C. M. Reinhart (2006). "When in peril, retrench: Testing the portfolio channel of contagion," Journal of International Economics 69 (1), 203-230.

[6] Brennan, M. J. (1993). "Agency and Asset Pricing," working paper, UCLA.

[7] Brown, K., W. Harlow, and L. Starks (1996). "Of Tournaments and Temptations: An Analysis of Managerial Incentives in the Mutual Fund Industry," Journal of Finance 51, 85-110.

[8] Chen, H.-L., and G. Pennacchi (2009). "Does Prior Performance Affect a Mutual Fund's Choice of Risk? Theory and Further Empirical Evidence," Journal of Financial and Quantitative Analysis 44 (4), 745-775.

[9] Chevalier, J., and G. Ellison (1997). "Risk Taking by Mutual Funds as a Response to Incentives," Journal of Political Economy 105, 1167-1200.

[10] Coval, J., and T. Moskowitz (1999). "Home Bias at Home: Local Equity Preference in Domestic Portfolios," Journal of Finance 54 (5), 2045-2074.

[11] Cuoco, D., and R. Kaniel (2011). "Equilibrium Prices in the Presence of Delegated Portfolio Management," Journal of Financial Economics 101, 264-269. 
[12] Das, S., and R. Sundaram (1998a). "On the Regulation of Mutual Fund Fee Structures," NBER Working Paper 6639.

[13] Das, S., and R. Sundaram (1998b). "Fee Speech: Adverse Selection and the Regulation of Mutual Fund Fees," NBER Working Paper 6644.

[14] Dybvig, P., H. Farnsworth, and J. Carpenter (2010). "Portfolio Performance and Agency," Review of Financial Studies 23 (1), 1-23.

[15] Eichberger, J., S. Grant, and S. P. King (1999). "On Relative Performance Contracts and Fund Manager's Incentives," European Economic Review 43, 135-161.

[16] Goriaev, A., F. Palomino, and A. Prat (2000). "Mutual Fund Tournament: Risk Taking Incentives Induced By Ranking Objectives," Working Paper CentER, Tilburg University, No 2000-94.

[17] Grinblatt, M., and S. Titman (1989). "Adverse Risk Incentives and the Design of Performance Based Contracts," Management Science 35, 807-822.

[18] Heinkel, R., and N. M. Stoughton (1994). "The Dynamics of Portfolio Management Contracts," Review of Financial Studies 7, 351-387.

[19] Koski, J., and J. Pontiff (1999). "How are Derivatives Used: Evidence from the Mutual Fund Industry," Journal of Finance 54 (2), 791-816.

[20] Ippolito, R. A. (1992). "Consumer Reaction to Measures of Poor Quality: Evidence from the Mutual Fund Industry," Journal of Law and Economics 35, 45-70.

[21] Kyle, P. (1985). "Continuous Auction and Insider Trading," Econometrica 53 (6), 1315-1336.

[22] Lettau, M. (1997). "Explaining the Facts with Adaptative Agents: The Case of Mutual Fund Flows," Journal of Economic Dynamics and Control 21, 1117-1147.

[23] Ou-Yang, H. (2003). "Optimal Contracts in a Continuous-Time Delegated Portfolio Management Problem," Review of Financial Studies 16, 173-208. 
[24] Palomino, F. (2005). "Relative Performance Objectives in Financial Markets," Journal of Financial Intermediation 14, 351-375.

[25] Pinheiro, M., (2008). "Loyalty, peer group effects, and 401(k)," Quarterly Review of Economics and Finance 48 (1), 94-122,

[26] Sensoy, B. (2009). "Performance evaluation and self-designated benchmark indexes in the mutual fund industry," Journal of Financial Economics 92 (1), 25-39.

[27] Shelef, O. (2013). "Incentive Thresholds, Risk Taking, and Performance: Evidence from Hedge Funds," working paper, Haas School of Business.

[28] Sirri, E. R., and P. Tufano (1998). "Costly Search and Mutual Fund Flows," Journal of Finance $53,1589-1622$.

[29] Starks, L. T. (1987). "Performance Incentive Fees: An Agency Theoretic Approach," Journal of Financial and Quantitative Analysis 22, 17-32.

[30] Taylor, J. (2003). "Risk-Taking Behavior in Mutual Fund Tournaments," Journal of Economic Behavior and Organization 50 (3), 373-83.

[31] Tesar, L., and I. Werner (1995). "Home Bias and High Turnover," Journal of International Money and Finance 14 (4), 467-492. 


\section{Appendix}

\section{A Proof of Proposition 1}

We start by conjecturing linear price and demand functions, i.e.,

$$
P=\lambda\left(\alpha_{1}+\alpha_{2}+u\right), \alpha_{i}=\beta_{i} \widetilde{s}_{i}
$$

Notice that symmetry will not be imposed until later on. By our distributional assumptions, we can write

$$
v \mid s_{i} \sim N\left(\frac{\sigma_{v}^{2}}{\sigma_{v}^{2}+\sigma_{\varepsilon}^{2}} s_{i}, \sigma_{v}^{2}-\frac{\sigma_{v}^{4}}{\sigma_{v}^{2}+\sigma_{\varepsilon}^{2}}\right)
$$

We can now calculate a few conditional moments that will later be of importance:

$$
\begin{aligned}
& \mathbb{E}\left[s_{j} \mid s_{i}\right]=\mathbb{E}\left[v \mid s_{i}\right]=\frac{\sigma_{v}^{2}}{\sigma_{v}^{2}+\sigma_{\varepsilon}^{2}} s_{i}:=D ; \\
& \mathbb{E}\left[\alpha_{j} \mid s_{i}\right]=\beta_{j} \frac{\sigma_{v}^{2}}{\sigma_{v}^{2}+\sigma_{\varepsilon}^{2}} s_{i} \\
& \mathbb{E}\left[\alpha_{j} v \mid s_{i}\right]= \beta_{j} \mathbb{E}\left[v^{2}+\varepsilon_{j} v \mid s_{i}\right]=\beta_{j} \mathbb{E}\left[v^{2} \mid s_{i}\right] \\
&= \beta_{j}\left[\sigma_{v}^{2}-\frac{\sigma_{v}^{4}}{\sigma_{v}^{2}+\sigma_{\varepsilon}^{2}}+D^{2}\right]:=\beta_{j} C . \\
& \mathbb{E}\left[\alpha_{j}^{2} \mid s_{i}\right]=\beta_{j}^{2} \mathbb{E}\left[\left(v^{2}+2 \varepsilon_{j} v+\varepsilon_{j}^{2}\right) \mid s_{i}\right]=\beta_{j}^{2}\left(C+\sigma_{\varepsilon}^{2}\right) ;
\end{aligned}
$$

Therefore, we can calculate the objective function of manager $i$ to be equal to ${ }^{17}$

$\mathbb{E}\left\{\left[\left(\alpha_{i}-\gamma \alpha_{j}\right)\left(v-\lambda\left(\alpha_{i}+\alpha_{j}+u\right)\right)\right] \mid s_{i}\right\}=\alpha_{i} D-\lambda \alpha_{i}^{2}-\lambda \alpha_{i} \beta_{j} D-\gamma \beta_{j} C+\lambda \alpha_{i} \gamma \beta_{j} D+\gamma \lambda \beta_{j}^{2}\left(C+\sigma_{\varepsilon}^{2}\right)$.

Taking the first derivative with respect to $\alpha_{i}$ and setting it equal to zero we have:

$$
D-2 \lambda \alpha_{i}-\lambda \beta_{j} D+\lambda \gamma \beta_{j} D=0
$$

or

$$
\alpha_{i}=\frac{D}{2 \lambda}\left[1-\lambda \beta_{j}(1-\gamma)\right]=\frac{\left[1-\lambda \beta_{j}(1-\gamma)\right]}{2 \lambda} \frac{\sigma_{v}^{2}}{\sigma_{v}^{2}+\sigma_{\varepsilon}^{2}} s_{i} .
$$

\footnotetext{
${ }^{17}$ We ignore $\phi$ here.
} 
So,

$$
\beta_{i}=\frac{\left[1-\lambda \beta_{j}(1-\gamma)\right]}{2 \lambda} \frac{\sigma_{v}^{2}}{\sigma_{v}^{2}+\sigma_{\varepsilon}^{2}} .
$$

Now we impose symmetry, $\beta_{i}=\beta_{j}=\beta$, getting

$$
\begin{gathered}
2 \lambda \beta=[1-\lambda \beta(1-\gamma)] \frac{\sigma_{v}^{2}}{\sigma_{v}^{2}+\sigma_{\varepsilon}^{2}} \\
\Leftrightarrow \\
\lambda \beta\left[2+(1-\gamma) \frac{\sigma_{v}^{2}}{\sigma_{v}^{2}+\sigma_{\varepsilon}^{2}}\right]=\frac{\sigma_{v}^{2}}{\sigma_{v}^{2}+\sigma_{\varepsilon}^{2}},
\end{gathered}
$$

or

$$
\lambda \beta=\frac{\sigma_{v}^{2}}{2\left(\sigma_{v}^{2}+\sigma_{\varepsilon}^{2}\right)+(1-\gamma) \sigma_{v}^{2}}
$$

Now we solve for $\lambda$ as function of $\beta$. For this we need to derive the price function, i.e.,

$$
P=\mathbb{E}\left[v \mid \beta\left(s_{i}+s_{j}\right)+u\right]=\frac{2 \beta \sigma_{v}^{2}}{4 \beta^{2}\left(\sigma_{v}^{2}+\frac{\sigma_{\varepsilon}^{2}}{2}\right)+\sigma_{u}^{2}}\left[\beta\left(s_{i}+s_{j}\right)+u\right],
$$

hence,

$$
\lambda=\frac{2 \beta \sigma_{v}^{2}}{4 \beta^{2}\left(\sigma_{v}^{2}+\frac{\sigma_{\varepsilon}^{2}}{2}\right)+\sigma_{u}^{2}} .
$$

Solving these two equations reveals:

$$
\beta=\sqrt{\frac{\sigma_{u}^{2}}{2(1-\gamma) \sigma_{v}^{2}+2 \sigma_{\varepsilon}^{2}}}, \quad \lambda=\frac{2 \sigma_{v}^{2} \sqrt{\frac{\sigma_{u}^{2}}{2(1-\gamma) \sigma_{v}^{2}+2 \sigma_{\varepsilon}^{2}}}}{\left(2 \sigma_{v}^{2}+\sigma_{\varepsilon}^{2}\right) \frac{\sigma_{u}^{2}}{(1-\gamma) \sigma_{v}^{2}+\sigma_{\varepsilon}^{2}}+\sigma_{u}^{2}} .
$$

\section{B Proof of Corollary 1}

We can easily calculate the expected payoff to investors of fund $i$ by using the derived equilibrium in Proposition 1:

$$
\begin{aligned}
\mathbb{E}[\pi(\gamma)] & =\varsigma \mathbb{E}\left[\alpha_{i}(v-P)\right]=\varsigma \mathbb{E}\left[\beta \widetilde{s}_{i}\left(v-\lambda\left(\beta \widetilde{s_{i}}+\beta \widetilde{s_{j}}+u\right)\right)\right] \\
& =\varsigma \beta \sigma_{v}^{2}-2 \beta^{2} \lambda \sigma_{v}^{2}-\beta^{2} \lambda \sigma_{\varepsilon}^{2}=\varsigma \beta\left[\sigma_{v}^{2}-\beta \lambda\left(2 \sigma_{v}^{2}+\sigma_{\varepsilon}^{2}\right)\right]
\end{aligned}
$$




$$
\begin{aligned}
& =\varsigma \sigma_{v}^{2} \sqrt{\frac{\sigma_{u}^{2}}{2(1-\gamma) \sigma_{v}^{2}+2 \sigma_{\varepsilon}^{2}}}\left(1-\frac{2 \sigma_{v}^{2}+\sigma_{\varepsilon}^{2}}{2\left(\sigma_{v}^{2}+\sigma_{\varepsilon}^{2}\right)+(1-\gamma) \sigma_{v}^{2}}\right) \\
& =\varsigma \sigma_{v}^{2} \sqrt{\frac{\sigma_{u}^{2}}{2(1-\gamma) \sigma_{v}^{2}+2 \sigma_{\varepsilon}^{2}}}\left(\frac{\sigma_{\varepsilon}^{2}+(1-\gamma) \sigma_{v}^{2}}{2\left(\sigma_{v}^{2}+\sigma_{\varepsilon}^{2}\right)+(1-\gamma) \sigma_{v}^{2}}\right) \\
& =\varsigma \sigma_{v}^{2} \sqrt{\frac{\sigma_{u}^{2}}{2}\left(\frac{\sqrt{\sigma_{\varepsilon}^{2}+(1-\gamma) \sigma_{v}^{2}}}{2\left(\sigma_{v}^{2}+\sigma_{\varepsilon}^{2}\right)+(1-\gamma) \sigma_{v}^{2}}\right) .}
\end{aligned}
$$

\section{Proof of Corollary 2}

To prove the statement on the corollary we just need to show that $\frac{d}{d \gamma} \mathbb{E}[\pi(\gamma)]<0$. But

$$
\mathbb{E}[\pi(\gamma)]=\varsigma \sigma_{v}^{2} \sqrt{\frac{\sigma_{u}^{2}}{2}}\left(\frac{\sqrt{\sigma_{\varepsilon}^{2}+(1-\gamma) \sigma_{v}^{2}}}{2\left(\sigma_{v}^{2}+\sigma_{\varepsilon}^{2}\right)+(1-\gamma) \sigma_{v}^{2}}\right),
$$

and, hence,

$$
\begin{aligned}
\frac{d}{d \gamma} \mathbb{E}[\pi(\gamma)] & =\varsigma\left[\sigma_{v}^{2} \sqrt{\frac{\sigma_{u}^{2}}{2}}\right] \frac{d}{d \gamma}\left(\frac{\sqrt{\sigma_{\varepsilon}^{2}+(1-\gamma) \sigma_{v}^{2}}}{2\left(\sigma_{v}^{2}+\sigma_{\varepsilon}^{2}\right)+(1-\gamma) \sigma_{v}^{2}}\right) \\
& =\varsigma \frac{\left[\sigma_{v}^{2} \sqrt{\frac{\sigma_{u}^{2}}{2}}\right]\left\{-\frac{1}{2} \sigma_{v}^{2} \frac{\left[2 \sigma_{\varepsilon}^{2}+(3-\gamma) \sigma_{v}^{2}\right]}{\sqrt{\sigma_{\varepsilon}^{2}+(1-\gamma) \sigma_{v}^{2}}}+\sigma_{v}^{2} \sqrt{\sigma_{\varepsilon}^{2}+(1-\gamma) \sigma_{v}^{2}}\right\}}{\left[2\left(\sigma_{v}^{2}+\sigma_{\varepsilon}^{2}\right)+(1-\gamma) \sigma_{v}^{2}\right]^{2}} \\
& =\varsigma \frac{\left[\sigma_{v}^{2} \sqrt{\frac{\sigma_{u}^{2}}{2}}\right] \sqrt{\sigma_{\varepsilon}^{2}+(1-\gamma) \sigma_{v}^{2}}\left(\sigma_{v}^{2}\right)}{\left[2\left(\sigma_{v}^{2}+\sigma_{\varepsilon}^{2}\right)+(1-\gamma) \sigma_{v}^{2}\right]^{2}}\left\{-\frac{1}{2} \frac{\left[2 \sigma_{\varepsilon}^{2}+(3-\gamma) \sigma_{v}^{2}\right]}{\left(\sigma_{\varepsilon}^{2}+(1-\gamma) \sigma_{v}^{2}\right)}+1\right\} \\
& =\varsigma \frac{\sigma_{v}^{2}\left[\sigma_{v}^{2} \sqrt{\frac{\sigma_{u}^{2}}{2}}\right] \sqrt{\sigma_{\varepsilon}^{2}+(1-\gamma) \sigma_{v}^{2}}}{\left[2\left(\sigma_{v}^{2}+\sigma_{\varepsilon}^{2}\right)+(1-\gamma) \sigma_{v}^{2}\right]^{2}}\left\{\frac{2\left(\sigma_{\varepsilon}^{2}+(1-\gamma) \sigma_{v}^{2}\right)-\left[2 \sigma_{\varepsilon}^{2}+(3-\gamma) \sigma_{v}^{2}\right]}{2\left(\sigma_{\varepsilon}^{2}+(1-\gamma) \sigma_{v}^{2}\right)}\right\} \\
& =\varsigma \frac{\sigma_{v}^{2}\left[\sigma_{v}^{2} \sqrt{\frac{\sigma_{u}^{2}}{2}}\right] \sqrt{\sigma_{\varepsilon}^{2}+(1-\gamma) \sigma_{v}^{2}}}{\left[2\left(\sigma_{v}^{2}+\sigma_{\varepsilon}^{2}\right)+(1-\gamma) \sigma_{v}^{2}\right]^{2}}\left\{\frac{-(1+\gamma) \sigma_{v}^{2}}{2\left(\sigma_{\varepsilon}^{2}+(1-\gamma) \sigma_{v}^{2}\right)}\right\} \\
& =\varsigma \frac{\sigma_{v}^{2}}{2\left(\sigma_{v}^{2}+\sigma_{\varepsilon}^{2}\right)+(1-\gamma) \sigma_{v}^{2}}\left\{\frac{-(1+\gamma) \sigma_{v}^{2}}{2\left(\sigma_{\varepsilon}^{2}+(1-\gamma) \sigma_{v}^{2}\right)}\right\} \mathbb{E}[\pi(\gamma)] \\
& <0
\end{aligned}
$$

So, the higher the parameter that determines the manager's payoff dependence on relative performance, the lower the ex-ante expected profits of fund investors. Investors would rather have a fund manager that cares only about absolute performance. 


\section{Proof of Corollary 3}

(i) and $(i v)$ : Recall that

$$
\beta=\sqrt{\frac{\sigma_{u}^{2}}{2(1-\gamma) \sigma_{v}^{2}+2 \sigma_{\varepsilon}^{2}}}, \quad \lambda=\frac{2 \sigma_{v}^{2} \sqrt{\frac{\sigma_{u}^{2}}{2(1-\gamma) \sigma_{v}^{2}+2 \sigma_{\varepsilon}^{2}}}}{\left(2 \sigma_{v}^{2}+\sigma_{\varepsilon}^{2}\right) \frac{\sigma_{u}^{2}}{(1-\gamma) \sigma_{v}^{2}+\sigma_{\varepsilon}^{2}}+\sigma_{u}^{2}} .
$$

Notice that

$$
\frac{d}{d \gamma} \beta=\frac{d}{d \gamma} \sqrt{\frac{\sigma_{u}^{2}}{2(1-\gamma) \sigma_{v}^{2}+2 \sigma_{\varepsilon}^{2}}}>0
$$

So, $\beta$ increases with the relative performance pay parameter. This means that the higher the importance of the relative pay, the more aggressively will fund managers trade in their signals as claimed in $(i v)$. And, after some algebra, we can re-write $\lambda$ as

$$
\lambda=\frac{1}{\beta} \frac{\sigma_{v}^{2}}{2\left(\sigma_{v}^{2}+\sigma_{\varepsilon}^{2}\right)+(1-\gamma) \sigma_{v}^{2}},
$$

hence,

$$
\frac{d}{d \gamma} \lambda=-\frac{1}{\beta^{2}} \frac{d \beta}{d \gamma} \frac{\sigma_{v}^{2}}{2\left(\sigma_{v}^{2}+\sigma_{\varepsilon}^{2}\right)+(1-\gamma) \sigma_{v}^{2}}+\frac{d}{d \gamma}\left(\frac{\sigma_{v}^{2}}{2\left(\sigma_{v}^{2}+\sigma_{\varepsilon}^{2}\right)+(1-\gamma) \sigma_{v}^{2}}\right) \frac{1}{\beta} .
$$

Plugging in the appropriate derivatives and after some algebra we can re-write the above expression as

$$
\frac{d}{d \gamma} \lambda=\frac{\beta \sigma_{v}^{4}}{\sigma_{u}^{2}\left[2\left(\sigma_{v}^{2}+\sigma_{\varepsilon}^{2}\right)+(1-\gamma) \sigma_{v}^{2}\right]}\left[\frac{(1-\gamma) \sigma_{v}^{2}-2 \sigma_{v}^{2}}{2\left(\sigma_{v}^{2}+\sigma_{\varepsilon}^{2}\right)+(1-\gamma) \sigma_{v}^{2}}\right]<0 .
$$

Therefore, $\frac{d}{d \gamma} \frac{1}{\lambda}>0$, and depth is increasing in $\gamma$.

(ii) : Now let's turn to the price informativeness, for this we need

$$
\operatorname{Var}[v \mid P]=\sigma_{v}^{2}-\frac{\left(2 \lambda \beta \sigma_{v}^{2}\right)^{2}}{\lambda^{2}\left[4 \beta^{2} \sigma_{v}^{2}+2 \beta^{2} \sigma_{\varepsilon}^{2}+\sigma_{u}^{2}\right]}=\frac{2 \beta^{2} \sigma_{v}^{2} \sigma_{\varepsilon}^{2}+\sigma_{u}^{2} \sigma_{v}^{2}}{4 \beta^{2} \sigma_{v}^{2}+2 \beta^{2} \sigma_{\varepsilon}^{2}+\sigma_{u}^{2}},
$$

then,

$$
\frac{d}{d \gamma} \operatorname{Var}[v \mid P]=\left(\frac{d}{d \beta} \operatorname{Var}[v \mid P]\right)\left(\frac{d}{d \gamma} \beta\right)
$$

However,

$$
\frac{d}{d \beta} \operatorname{Var}[v \mid P]=\left[\frac{1}{4 \beta^{2} \sigma_{v}^{2}+2 \beta^{2} \sigma_{\varepsilon}^{2}+\sigma_{u}^{2}}\right]^{2}\left(-8 \beta \sigma_{v}^{2} \sigma_{\varepsilon}^{2} \sigma_{u}^{2}\right)<0,
$$

and $\frac{d}{d \gamma} \beta>0$. Therefore,

$$
\frac{d}{d \gamma} \operatorname{Var}[v \mid P]=\left(\frac{d}{d \beta} \operatorname{Var}[v \mid P]\right)\left(\frac{d}{d \gamma} \beta\right)<0
$$


Since the variance of the asset payoff conditional on price decreases as $\gamma$ increases, one can say that higher relative performance leads to increased price informativeness. The first effect is similar to the effect in Kyle (1985) where an increase in aggressiveness leads to more revealing prices. The second effect is unique to the present setting. It comes about due to the presence of the relative performance objective function. So, the mechanism through which price informativeness is increased is simple, increased relative performance objectives leads to increased trading aggressiveness, which, in turn, much like in Kyle (1985), leads to more information being revealed through prices.

(iii) : Concerning adverse selection costs, we know that this is a zero sum market, the losses of noise traders is the (aggregate) gain obtained through informed trading (total profits of both funds). ${ }^{18}$ Therefore, the adverse selection cost faced by liquidity traders is just

$$
L(\gamma)=2 \frac{\mathbb{E}[\pi(\gamma)]}{\varsigma}=2 \sigma_{v}^{2} \sqrt{\frac{\sigma_{u}^{2}}{2}}\left(\frac{\sqrt{\sigma_{\varepsilon}^{2}+(1-\gamma) \sigma_{v}^{2}}}{2\left(\sigma_{v}^{2}+\sigma_{\varepsilon}^{2}\right)+(1-\gamma) \sigma_{v}^{2}}\right),
$$

and, since we already showed that $\frac{d}{d \gamma} \mathbb{E}[\pi(\gamma)]<0$, we can guarantee that $\frac{d}{d \gamma} L(\gamma)<0$. This indicates that liquidity traders are better off with more relative performance pay for fund managers. This is another expected result given that we have shown that markets get deeper as $\gamma$ increases, and we know that deeper markets favor liquidity-strained investors.

\section{E Proof of Proposition 2}

The structure of the equilibrium follows immediately from the Proof of Proposition 1, and the calculation for the coefficient of correlation between the two prices is trivial. Therefore, we are left with the burden of proof that the correlation coefficient is indeed increasing in either $\gamma_{m}$.

Notice that $\rho$ depends on $\gamma_{1}$ only through $\beta_{1}$ 's dependence on it. Hence, if we let $A$ denote a constant that is independent of $\beta_{1}$, we can write

$$
\rho=A \frac{\beta_{1}}{\sqrt{\left(4 \beta_{1}^{2} \sigma_{1}^{2}+2 \beta_{1}^{2} \sigma_{\varepsilon 1}^{2}+\sigma_{u 1}^{2}\right)}},
$$

\footnotetext{
${ }^{18}$ This result is independent of how the profits are distributed among owners, investors and managers of each fund.
} 
then

$$
\begin{aligned}
\frac{\partial \rho}{\partial \beta_{1}} & =A \frac{\partial\left(\frac{\beta_{1}}{\sqrt{\left(4 \beta_{1}^{2} \sigma_{1}^{2}+2 \beta_{1}^{2} \sigma_{\varepsilon 1}^{2}+\sigma_{u 1}^{2}\right)}}\right)}{\partial \beta_{1}}=A \frac{\frac{\partial}{\partial \beta_{1}}\left(\frac{\beta_{1}}{\sqrt{\left(4 \beta_{1}^{2} \sigma_{1}^{2}+2 \beta_{1}^{2} \sigma_{\varepsilon 1}^{2}+\sigma_{u 1}^{2}\right)}}\right)^{2}}{2 \frac{\beta_{1}}{\sqrt{\left(4 \beta_{1}^{2} \sigma_{1}^{2}+2 \beta_{1}^{2} \sigma_{\varepsilon 1}^{2}+\sigma_{u 1}^{2}\right)}}} \\
& =\frac{A \sqrt{\left(4 \beta_{1}^{2} \sigma_{1}^{2}+2 \beta_{1}^{2} \sigma_{\varepsilon 1}^{2}+\sigma_{u 1}^{2}\right)}}{2 \beta_{1}} \frac{\partial\left(\frac{\beta_{1}^{2}}{4 \beta_{1}^{2} \sigma_{1}^{2}+2 \beta_{1}^{2} \sigma_{\varepsilon 1}^{2}+\sigma_{u 1}^{2}}\right)}{\partial \beta_{1}} \\
& =\frac{A \sqrt{\left(4 \beta_{1}^{2} \sigma_{1}^{2}+2 \beta_{1}^{2} \sigma_{\varepsilon 1}^{2}+\sigma_{u 1}^{2}\right)}}{2 \beta_{1}} \frac{2 \beta_{1} \sigma_{u}^{2}}{\left(\sigma_{u}^{2}+4 \sigma_{1}^{2} \beta_{1}^{2}+2 \beta_{1}^{2} \sigma_{\varepsilon}^{2}\right)^{2}}>0 .
\end{aligned}
$$

Finally, using the fact that $\frac{\partial \beta_{1}}{\partial \gamma_{1}}>0$, we have $\frac{\partial \rho}{\partial \gamma_{1}}=\frac{\partial \rho}{\partial \beta_{1}} \frac{\partial \beta_{1}}{\partial \gamma_{1}}>0$. Identical calculations show the same result for $\gamma_{2}$.

\section{F Proof of Proposition 3}

To find manager $i$ 's profit in the case where both managers decide to be informed, we simply compute the following expected value:

$$
\begin{aligned}
\mathbb{E} \phi\left[\left(\alpha_{i}-\gamma \alpha_{j}\right)(v-P)\right] & =\phi \mathbb{E}\left[\left(\beta\left(\widetilde{s_{i}}-\gamma \widetilde{s_{j}}\right)\right)\left(v-\lambda\left(\beta\left(\widetilde{s_{i}}+\widetilde{s_{j}}\right)+u\right)\right)\right] \\
& =\phi\left[\beta(1-\gamma) \sigma_{v}^{2}-\lambda \beta^{2} \mathbb{E}\left(\widetilde{s_{i}}-\gamma \widetilde{s_{j}}\right)\left(\widetilde{s_{i}}+\widetilde{s_{j}}\right)\right] \\
& =\phi\left[\beta(1-\gamma) \sigma_{v}^{2}-\lambda \beta^{2} \mathbb{E}\left[{\widetilde{s_{i}}}^{2}+(1-\gamma) \widetilde{s_{i}} \widetilde{s_{j}}-\gamma{\widetilde{s_{j}}}^{2}\right]\right] \\
& =\phi\left[\beta(1-\gamma) \sigma_{v}^{2}-\lambda \beta^{2}(1-\gamma)\left(\sigma_{v}^{2}+\sigma_{\varepsilon}^{2}\right)-\lambda \beta^{2}(1-\gamma) \sigma_{v}^{2}\right] \\
& =\phi(1-\gamma)\left[\beta \sigma_{v}^{2}-\lambda \beta^{2}\left(2 \sigma_{v}^{2}+\sigma_{\varepsilon}^{2}\right)\right] \\
& =\phi(1-\gamma) \beta\left[\sigma_{v}^{2}-\frac{\sigma_{v}^{2}\left(2 \sigma_{v}^{2}+\sigma_{\varepsilon}^{2}\right)}{2\left(\sigma_{v}^{2}+\sigma_{\varepsilon}^{2}\right)+(1-\gamma) \sigma_{v}^{2}}\right] \\
& =\phi(1-\gamma) \beta \sigma_{v}^{2}\left[\frac{\sigma_{\varepsilon}^{2}+(1-\gamma) \sigma_{v}^{2}}{2\left(\sigma_{v}^{2}+\sigma_{\varepsilon}^{2}\right)+(1-\gamma) \sigma_{v}^{2}}\right] .
\end{aligned}
$$

Then, we can compute its derivative with respect to $\gamma$ :

$$
\frac{d}{d \gamma} \mathbb{E} \phi\left[\left(\alpha_{i}-\gamma \alpha_{j}\right)(v-P)\right]=\phi \sigma_{v}^{2} \frac{d \beta}{d \gamma} \frac{d}{d \gamma}\left\{(1-\gamma)\left[\frac{\sigma_{\varepsilon}^{2}+(1-\gamma) \sigma_{v}^{2}}{2\left(\sigma_{v}^{2}+\sigma_{\varepsilon}^{2}\right)+(1-\gamma) \sigma_{v}^{2}}\right]\right\}
$$




$$
\begin{aligned}
& =\phi \sigma_{v}^{2} \frac{d \beta}{d \gamma}\left[\frac{-\sigma_{\varepsilon}^{2}-(1-\gamma) \sigma_{v}^{2}}{2\left(\sigma_{v}^{2}+\sigma_{\varepsilon}^{2}\right)+(1-\gamma) \sigma_{v}^{2}}+\frac{(1-\gamma)\left\{-\sigma_{v}^{2}\left[2\left(\sigma_{v}^{2}+\sigma_{\varepsilon}^{2}\right)+(1-\gamma) \sigma_{v}^{2}\right]+\sigma_{v}^{2}\left[\sigma_{\varepsilon}^{2}+(1-\gamma) \sigma_{v}^{2}\right]\right\}}{\left[2\left(\sigma_{v}^{2}+\sigma_{\varepsilon}^{2}\right)+(1-\gamma) \sigma_{v}^{2}\right]^{2}}\right] \\
& =\phi \sigma_{v}^{2} \frac{d \beta}{d \gamma}\left\{-\frac{\sigma_{\varepsilon}^{2}+(1-\gamma) \sigma_{v}^{2}}{2\left(\sigma_{v}^{2}+\sigma_{\varepsilon}^{2}\right)+(1-\gamma) \sigma_{v}^{2}}-(1-\gamma) \frac{\sigma_{v}^{2}\left(2 \sigma_{v}^{2}+\sigma_{\varepsilon}^{2}\right)}{\left[2\left(\sigma_{v}^{2}+\sigma_{\varepsilon}^{2}\right)+(1-\gamma) \sigma_{v}^{2}\right]^{2}}\right\}<0,
\end{aligned}
$$

since the term inside curly brackets is negative and $\frac{d \beta}{d \gamma}>0$.

More importantly, given that each manager has to pay $c$ to be informed, an equilibrium with both informed requires that $\mathbb{E} \phi\left[\left(\alpha_{i}-\gamma \alpha_{j}\right)(v-P)\right]>c$. So, if there exists a $\bar{\gamma}$ such that $\mathbb{E} \phi\left[\left(\alpha_{i}-\bar{\gamma} \alpha_{j}\right)(v-P)\right]=c$, then for any $\gamma>\bar{\gamma}$ the inequality is violated, and no information is acquired. Conditional on the information being acquired, prices are more informative, but it may be the case that no information is acquired at all, rendering the last point moot.

\section{G Proof of Proposition 4}

Under the assumptions spelled out in the proposition, each manager has an expected profit of

$$
\begin{aligned}
\mathbb{E} \phi\left[\left(\alpha_{i}-\gamma \alpha_{j}\right)(v-P)\right] & =\left(\frac{1-\gamma}{3-\gamma}\right) \phi(1-\gamma) \beta \sigma_{v}^{2} \\
& =\left(\frac{1-\gamma}{3-\gamma}\right) \phi(1-\gamma) \sqrt{\frac{\sigma_{u}^{2}}{2(1-\gamma) \sigma_{v}^{2}}} \sigma_{v}^{2} \\
& =\phi \frac{\sqrt{(1-\gamma)^{3}}}{3-\gamma} \sqrt{\frac{\sigma_{u}^{2} \sigma_{v}^{2}}{2}}:=E .
\end{aligned}
$$

Hence, we can write (29) as $\frac{E}{\bar{c}}\left[\frac{-4 \beta^{2} \sigma_{v}^{4}}{4 \beta^{2} \sigma_{v}^{2}+\sigma_{u}^{2}}\right]+\sigma_{v}^{2}$, and plugging in the value of $\beta$ and $E$ gives:

$$
\sigma_{v}^{2}\left\{1-\frac{2}{\bar{c}} \phi \sqrt{\frac{\sigma_{u}^{2} \sigma_{v}^{2}}{2}}\left[\frac{(1-\gamma)^{\frac{3}{2}}}{(3-\gamma)^{2}}\right]\right\} .
$$

And, finally, differentiating this expression with respect to $\gamma$ we get

$$
\frac{2}{\bar{c}} \phi \sigma_{v}^{2} \sqrt{\frac{\sigma_{u}^{2} \sigma_{v}^{2}}{2}} \frac{(1-\gamma)^{0.5}}{(3-\gamma)^{3}}\left(\frac{5}{2}+\frac{\gamma}{2}\right)>0 .
$$

So, expected conditional variance of prices is increasing in $\gamma$, hence prices are less informative as $\gamma$ increases. 
Figure 1: Price Informativeness and $\gamma$

Inverse Expecte

(measured by the
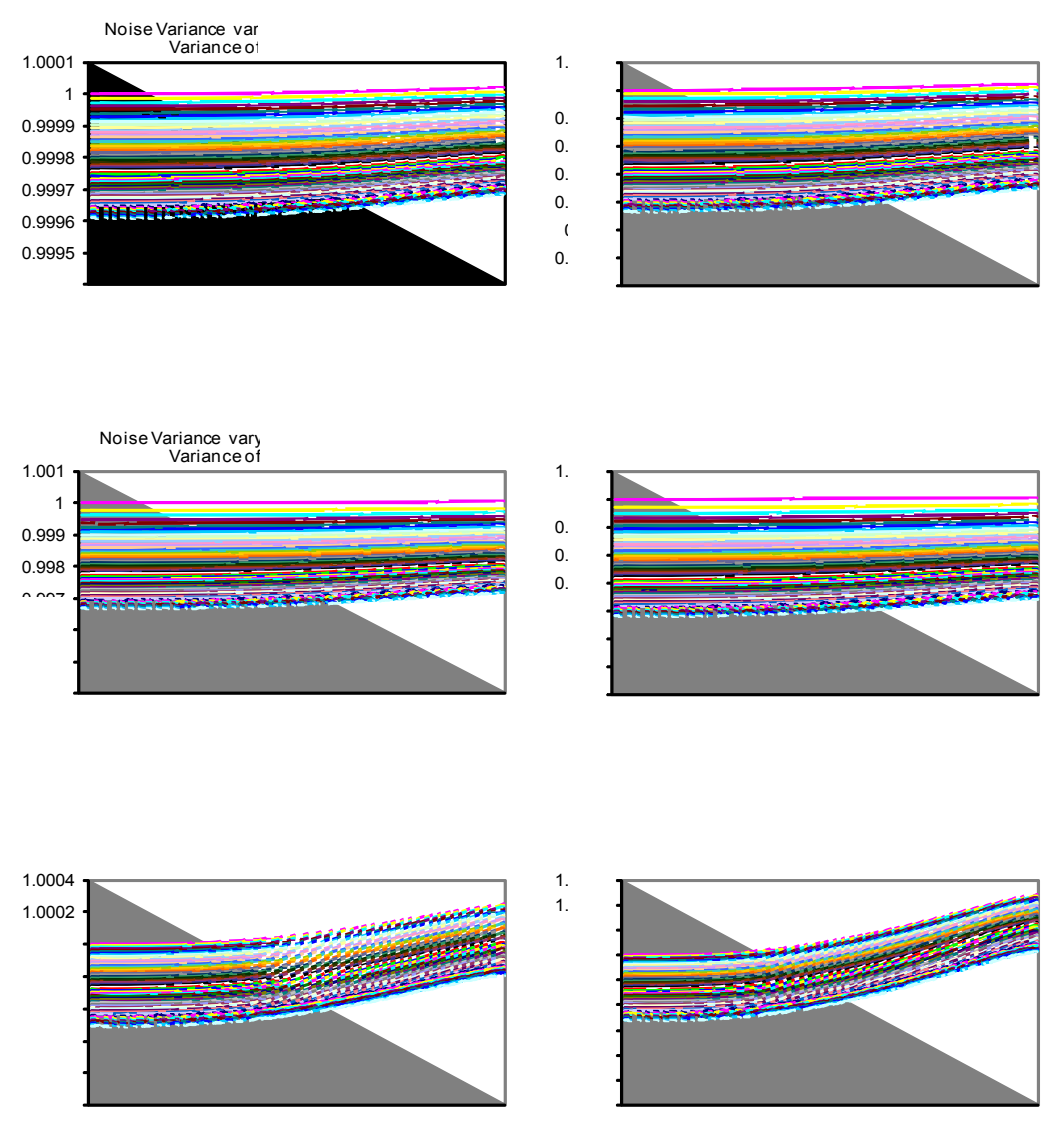

Source: Authors' calculations.

Note: We picture the expected conditional variance of prices, which is inversely related to the informational content of prices, as a function of relative performance concerns, denoted by $\gamma$. In all simulations, costs are assumed to be uniformly distributed on the unit interval and $\phi$ is set to 0.1 (using alternative values for $\phi$ does not alter the behavior). The variance of payoffs, $\sigma_{v}^{2}$, is set to 0.01 , with results again being robust to other parameter values chosen. Each curve corresponds to a different value of the noise variance, $\sigma_{u}^{2}$, within the range indicated in increments of 0.005 . The calculated values of the expected conditional variance of prices are then rescaled to equal 1 when $\gamma$ is 0 and the noise variance is at the minimum of its set range. 
Figure 2: Low $\frac{\sigma_{v}^{2}}{\sigma_{u}^{2}}$ Case (varying $\sigma_{u}^{2}$ from 0.6 to 0.6315 , with $\sigma_{v}^{2}=0.15$ and $\phi=0.1$ ) Expected Pri

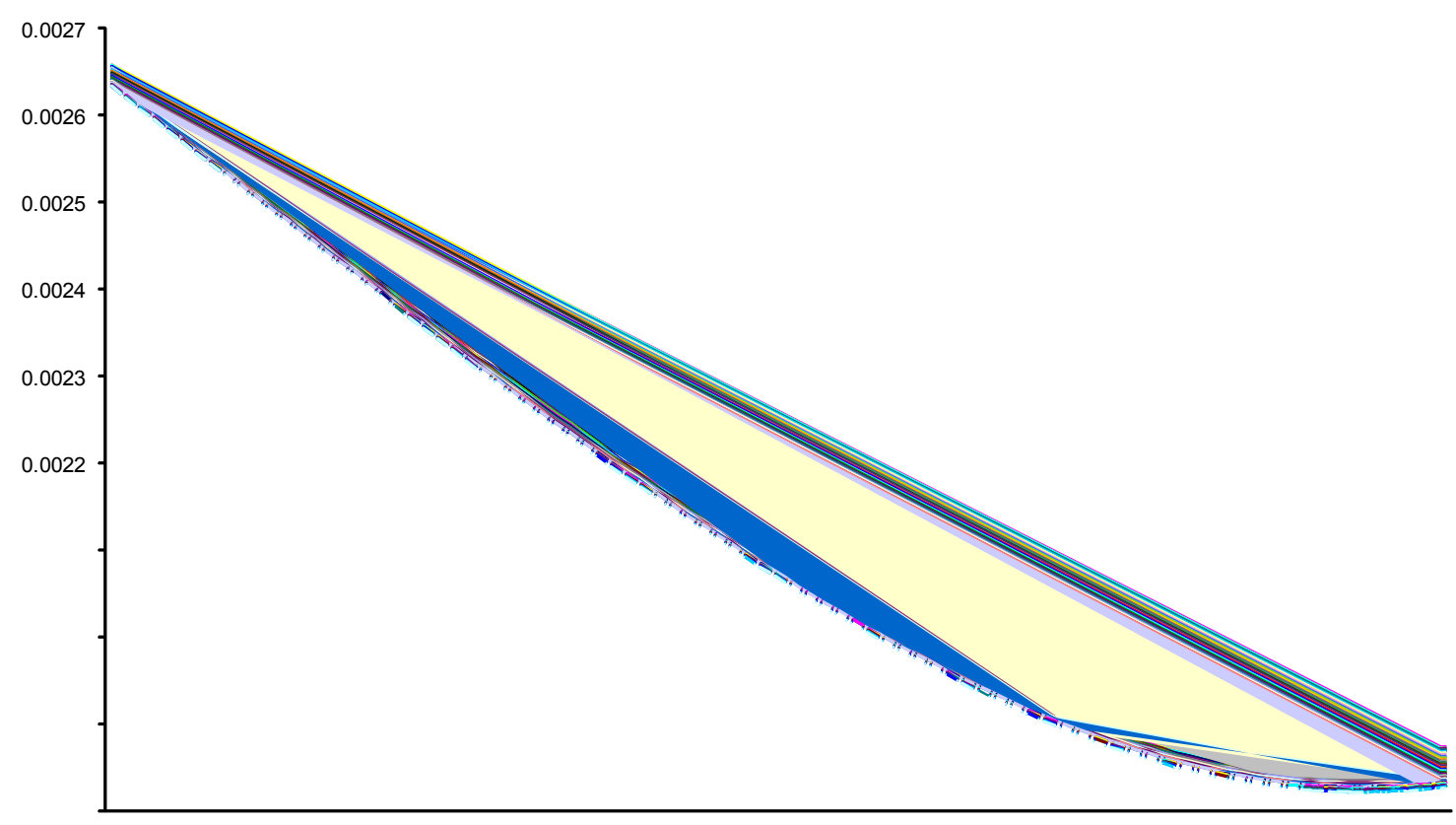


Figure 3: Higher $\frac{\sigma_{v}^{2}}{\sigma_{u}^{2}}$ Case (Varying $\sigma_{u}^{2}$ from 0.2 to 0.2315 , with $\sigma_{v}^{2}=0.15$ and $\phi=0.1$ ) Expected Pri

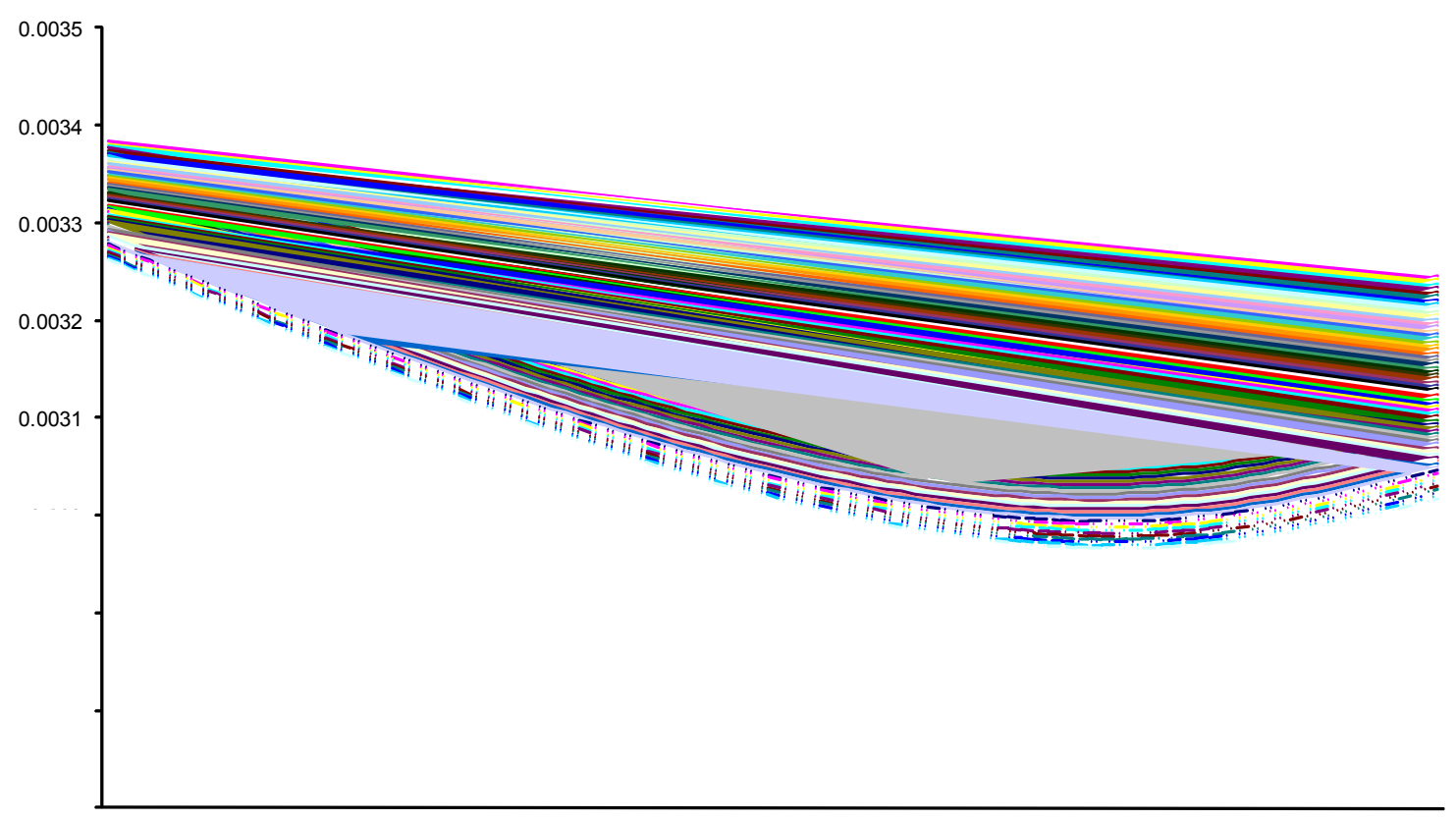


Figure 4: Very High $\frac{\sigma_{v}^{2}}{\sigma_{u}^{2}}$ Case (Varying $\sigma_{u}^{2}$ from 0.0005 to 0.032 , with $\sigma_{v}^{2}=0.15, \phi=0.1$ ) Expected Pri

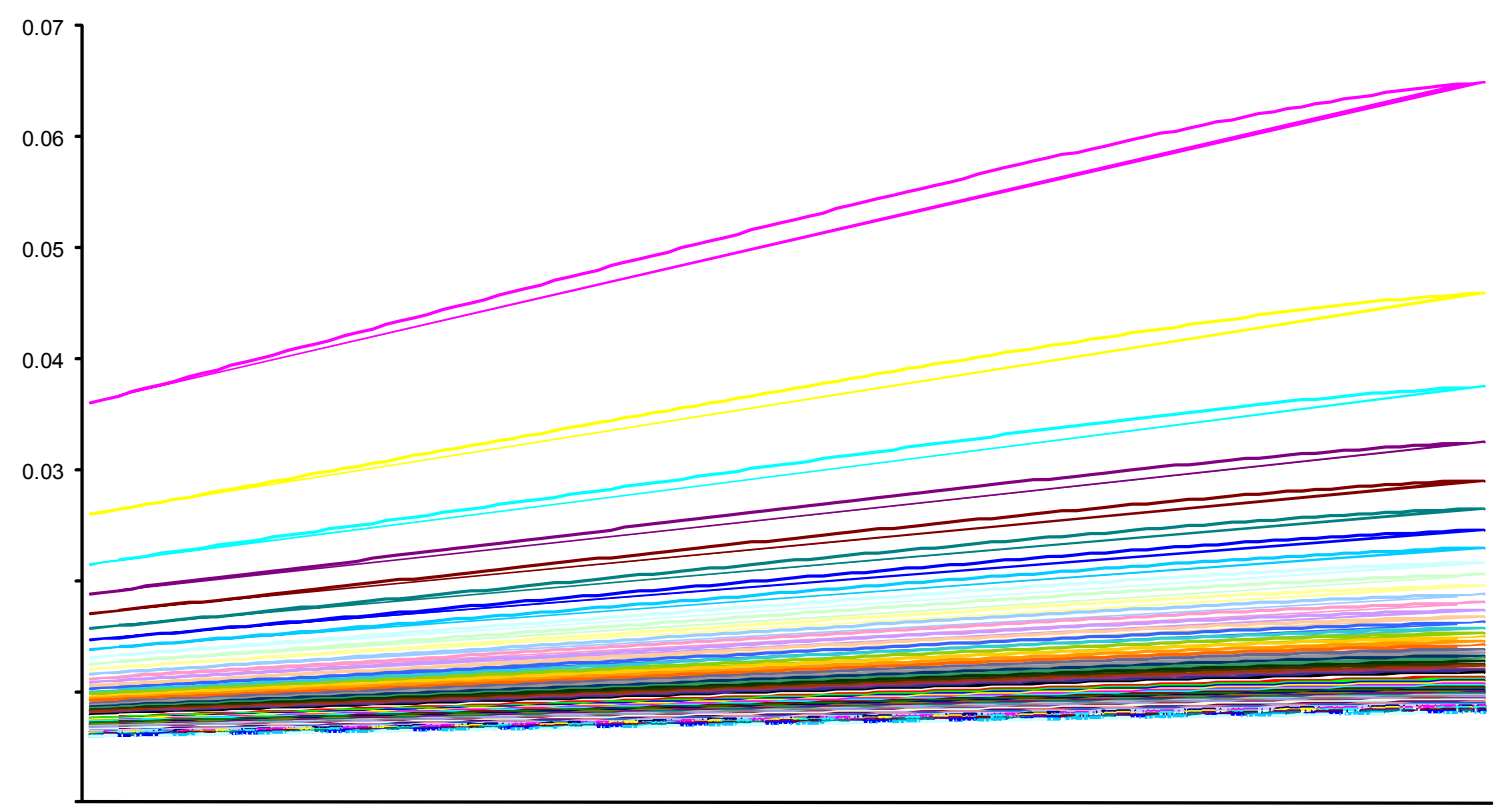

